\title{
Endothelial Progenitor Cells Physiology and Metabolic Plasticity in Brain Angiogenesis and Blood-Brain Barrier Modeling
}

\author{
Natalia A. Malinovskaya, Yulia K. Komleva, Vladimir V. Salmin, Andrey V. Morgun, \\ Anton N. Shuvaev, Yulia A. Panina, Elizaveta B. Boitsova and Alla B. Salmina*
}

Research Institute of Molecular Medicine \& Pathobiochemistry, Krasnoyarsk State Medical University named after Prof. V.F. Voino-Yasenetsky, Krasnoyarsk, Russia

\section{OPEN ACCESS}

Edited by:

Antonio Colantuoni,

University of Naples Federico II, Italy

Reviewed by:

Dominga Lapi,

University of Pisa, Italy

Sophia Ran,

Southern Illinois University

Carbondale, USA

Pasquale Pagliaro,

University of Turin, Italy

*Correspondence:

Alla B. Salmina

allasalmina@mail.ru

Specialty section:

This article was submitted to

Vascular Physiology,

a section of the journal

Frontiers in Physiology

Received: 01 September 2016 Accepted: 16 November 2016 Published: 01 December 2016

Citation:

Malinovskaya NA, Komleva YK Salmin W, Morgun AV, Shuvaev AN,

Panina YA, Boitsova EB and

Salmina AB (2016) Endothelial

Progenitor Cells Physiology and

Metabolic Plasticity in Brain

Angiogenesis and Blood-Brain Barrier

Modeling. Front. Physiol. 7:599

doi: 10.3389/fphys.2016.00599
Currently, there is a considerable interest to the assessment of blood-brain barrier (BBB) development as a part of cerebral angiogenesis developmental program. Embryonic and adult angiogenesis in the brain is governed by the coordinated activity of endothelial progenitor cells, brain microvascular endothelial cells, and non-endothelial cells contributing to the establishment of the BBB (pericytes, astrocytes, neurons). Metabolic and functional plasticity of endothelial progenitor cells controls their timely recruitment, precise homing to the brain microvessels, and efficient support of brain angiogenesis. Deciphering endothelial progenitor cells physiology would provide novel engineering approaches to establish adequate microfluidically-supported BBB models and brain microphysiological systems for translational studies.

Keywords: endothelial progenitor cells, blood-brain barrier (BBB), neurovascular unit, Angiogenesis, Nicotinamide adenine dinucleotide (NAD+)

Abbreviations: Ado, adenosine; ADP, adenosine diphosphate; AMP, adenosine monophosphate; AMPK, AMP-activated protein kinase; ATP, adenosine triphosphate; BBB, blood-brain barrier; BMEC, brain microvessel endothelial cell; BMSC, bone marrow stromal cell; cAMP, cyclic adenosine monophosphate; $\mathrm{CD}$, cluster of differentiation; CNS, central nervous system; CSF, colony-stimulating factor; CXCL12, chemokine (C-X-C-motif) ligand 12; CXCR4, C-X-C chemokine receptor 4; DLL4, delta-like ligand 4; E, day of embryonic development; EC, endothelial cell; EMMPRIN, extracellular matrix metalloproteinase inducer; eNOS, endothelial nitric oxide synthase; EPC, endothelial progenitor cell; Epo, erythropoietin; FA, fatty acid; GLUT, glucose transporter; HIF-1, hypoxia inducible factor-1; HSC, hematopoietic stem cell; IGF, insulin-like growth factor; LDH, lactate dehydrogenase; MCT, monocarboxylate transporter; MIF, macrophage migration inhibitory factor; MMP, matrix metalloproteinase; MPS, microphysiological system; MSC, mesenchymal stem cell; NAD+, nicotinamide adenine dinucleotide; NADH, nicotinamide adenine dinucleotide reduced; NAMPT, nicotinamide phosphorybosyltransferase; NG2, NG2 chondroitin sulfate proteoglycan; NICD, Notch-protein intracellular cytoplasmic domain; NO, nitric oxide; NVU, neurovascular unit; OXPHOS, oxidative phosphorylation; P, day of postnatal development; PDGF, platelet-derived growth factor; PGC- $1 \alpha$, peroxisome proliferator-activated receptor $\gamma$ coactivator $1 \alpha$; PPAR $\gamma$, peroxisome proliferator-activated receptor $\gamma$; PPP, pentose phosphate pathway; RGS5, regulator of G-protein signaling 5; ROS, reactive oxygen species; SIRT, sirtuin; SDF-1, stromal cell-derived factor-1; TCA, tricarboxylic acid cycle; TfR, transferrin receptor; TGF $\beta$, transforming growth factor $\beta$; TNF $\alpha$, tumor necrosis factor $\alpha$; VCAM-1, vascular cell adhesion molecule-1; VEGF, vascular endothelial growth factor; VEGFR, vascular endothelial growth factor receptor; VLA-4, very late antigen-4; vWF, von Willebrand factor; Wnt, Wnt-signaling pathway. 


\section{ENDOTHELIAL PROGENITOR CELLS: ORIGIN AND GENERAL CHARACTERISTICS}

Neurovascular unit (NVU) consisted of cerebral microvessel endothelial cells, pericytes, astrocytes, neurons, and microglia is a structural and functional basis of the blood-brain barrier (BBB). NVU/BBB is actively involved in the regulation of crucial physiological processes within the brain, but is dramatically compromised in almost all the types of brain pathology (neurodevelopmental disorders, neurodegeneration, trauma, ischemia, neuroinflammation, neuroinfection etc.).

Brain microvascular endothelial cells (BMEC) represent one of the most interesting subpopulations of endothelial cells (EC) due to their specific properties required for the appropriate functioning of these cells: (i) regulation of cerebral blood circulation, (ii) selective and controlled permeability of the blood-brain barrier (BBB). In contrast to endothelial cells of non-cerebral localization, BMEC are characterized by high expression of tight junctions, high electrical resistance, low fenestration, small perivascular space, high prevalence of insulin and transferrin receptors, relatively big number of mitochondria (Stamatovic et al., 2008; Salmina et al., 2014). As it was demonstrated (De Bock et al., 2013), metabolic plasticity of endothelial cells allows rapid switching to active growth upon stimulation, i.e., under the conditions supporting establishment of tip or stalk cells phenotypes with the corresponding proliferative and migratory activity. Thus, metabolism of endothelial cells is considered as a major driver of angiogenesis and might serve as a marker of endothelial dysfunction seen in cardiovascular and cerebrovascular diseases (Eelen et al., 2015). However, another question arises on the metabolic activity of endothelial progenitor cells (EPC) that are responsible for vessel development and (re)endothelialization.

Currently, there is considerable interest to the assessment of BBB-related angiogenesis in developing and adult brain. Development of NVU critically depends on the availability of EPC that originate from embryonic hemangioblasts and hematopoietic stem cells and form the primary vascular plexus (Rae et al., 2011a). Embryonic vasculogenesis and establishment of BBB is driven by newly formed EPC migrating from the sites of hematopoietic stem cells (HSC) development. Bone marrow starts to function as a source of HSC just before birth whereas in embryogenesis, multi-lineage hematopoietic progenitors exist in the extraembryonic yolk sac at E8.25, in the placenta and embryonic aorta-gonad-mesonephros region at E10, and in the fetal liver at E11.0 in mice (Coşkun et al., 2014). Later, in the postnatal brain, EPC may also come from the bone-marrow hematopoietic niches, but their role in the endothelialization, maturation and maintenance of the structural and functional integrity of $\mathrm{BBB}$ is not clear yet.

The term "endothelial progenitor cells" initially covered various subsets of circulating progenitors derived from bonemarrow pluripotent stem cells and hemangioblasts. EPC are involved in vessel development and regeneration, being recruited from the bone-marrow to the peripheral blood, displaying immunopositivity for CD34, CD45, CD133, VEGFR2, c-kit, and, presumably existing as hematopoietic cells with pro-angiogenic activity in vitro and in vivo (Richardson and Yoder, 2011; Yoder, 2012). In adults, there are two origins of EPC: (i) hematopoietic origin (EPC derived from bone marrow multipotent hemangioblasts [VEGFR2 $(+) \mathrm{VE}-$ cadherin $(+) \mathrm{CD} 45(-)$ and mesenchymal stem cells (MSC) $(\mathrm{CD} 73(+) \mathrm{CD} 90(+) \mathrm{CD} 105(+) \mathrm{CD} 34(-) \mathrm{CD} 45(-)]$; (ii) and nonhematopoietic origin (EPC found at the sites of extensive angiogenesis but demonstrating no signs of hematopoietic origin, being, probably, derived from tissue multipotent cells) (Chao and Hirschi, 2010; Leeper et al., 2010; Boxall and Jones, 2012).

Bone-marrow-derived MSC possess the ability to migrate though the $\mathrm{BBB}$ in vivo and in vitro models without evident alterations in the barrier's integrity (Matsushita et al., 2011). Interestingly, there are the reciprocal effects of BMEC and MSC in hypoxic conditions: BMEC stimulate differentiation of MSC into EC, whereas MSC stimulate proliferation and migration of BMEC, thereby contributing to local angiogenesis associated with high BBB permeability (Liu et al., 2008).

Brain tissue multipotent cells express markers for mesenchymal stem cells (i.e., CD13, CD105) and pericytes (i.e., PDGFR- $\beta$ /CD140b, RGS5, Kir 6.1, NG2) and demonstrate strong multilineage potential (Paul et al., 2012). Relative similarity of MSC and pericytes is very well-known. In the adult brain, pericytes originate from the pre-existing pool or from some bone-marrow progenitors, may express wide spectrum of MSC markers in culture (CD44, CD73, CD90, CD105), contribute to the maintenance of $\mathrm{BBB}$ integrity being in the tight contact with EC (Pombero et al., 2016). Pericytes and endothelial cells are under the control of perivascular astrocytes that induce their differentiation needed for effective angiogenesis, thereby astroglial dysfunction may affect angiogenesis via dysregulation of $\mathrm{EPC} / \mathrm{EC} /$ pericytes interactions in cerebral microvessels. In several tissues, aberrant angiogenesis may be caused by the loss of pericytes number and inadequate proliferative response of EC (Ergul et al., 2015).

Thus, vasculogenesis (establishment of new vessels) is provided by EPC differentiated from embryonic hemangioblasts, or adult EPC, multipotent stem cells, and vessel wall-associated mesenchymal-like cells (mesoangioblasts) (Schmidt et al., 2007). Also, adult hemangioblasts have been detected in the CD133+population of peripheral blood (Loges et al., 2004). Sprouting or splitting angiogenesis (adult vascular growth) is provided by EC pre-existing in the vessel wall, but acquiring new phenotype (tip and stalk cells) and acting with the support of EPC coming from bone marrow or non-hematopoietic sources (Rae et al., 2011b), and pericytes.

In pathological conditions, angiogenesis and vascular remodeling are usually considered as significant components of brain tissue repair program after injury (hypoxic, ischemic, traumatic, inflammatory, toxic etc.), thus, EPC-mediated mechanisms should be of great importance. As an example, in stroke models, mobilization of EPC from bone marrow correlates to the severity of cerebral alterations (Arai et al., 2009). In Alzheimer's type of neurodegeneration, accumulation of amyloid results in excessive angiogenesis and leaky BBB whereas the levels of circulating EPC is dramatically reduced (Lee et al., 
2009; Biron et al., 2011). In autism, persistent remodeling of brain microvessels with the characteristics of splitting angiogenesis due to predominant proliferation of pericytes but not EC may affect neuronal connectivity (Azmitia et al., 2016). In diabetes mellitus, cerebral angiogenesis is exclusively enhanced and is associated with the appearance of non-functioning microvessels and decreased ratio of pericytes to EC (Prakash et al., 2012), but hypoxic injury of diabetic brain is characterized by delayed angiogenesis impeding brain tissue repair (Poittevin et al., 2015). In depression, insufficient angiogenesis is caused by the decreased number of EPC in the peripheral blood, low VEGF effects, and elevated levels of anti-angiogenic factors, whereas stimulation of cerebral angiogenesis is a marker of functional recovery (Boldrini et al., 2012; Yamada, 2016). In sum, it is clear that in almost all the types of brain pathology, deficits of circulating EPC attribute to the aberrant angiogenesis, thus suggesting impaired mobilization, migration of these cells to the brain.

Chemokines-, SDF1-, MMP9-, VEGF-, NO-dependent mechanisms are responsible for the mobilization of EPC from the bone marrow, whereas homing of the recruited cells is provided by molecules with high pro-angiogenic potential (i.e., VEGF, IGF, angiopoietins, cytokines, integrins) at the sites of developmental or pathological angiogenesis (Tilling et al., 2009; Caiado et al., 2011). Also, in addition to bone marrow-derived EPC, non-bone marrow-derived cells (tissue resident) could transform to EC and take part in the re-endothelizlization and angiogenesis (Balaji et al., 2013).

According to the current view, circulating EPC may differentiate into EC to restore the endothelial layer, may directly incorporate into injured endothelium, or may secrete pro-angiogenic factors (VEGF, SDF-1, PDGF etc.) or release microparticles to stimulate tip and stalk cells (Li et al., 2015b). Arrival of EPC to the sites of angiogenesis results in the establishment of functional connections between EPC and EC through the coordinated expression of adhesion proteins in a TNF $\alpha$-dependent manner (Prisco et al., 2015). EPC provide paracrine signaling to facilitate angiogenesis and phenotype changes in the pre-existing resident endothelial (or endothelial progenitor) cells in the tissue-specific manner at the sites of endothelial injury or high metabolic demand (Zhang et al., 2014). Either in embryonic and adult EPC, secretion of proangiogenic chemokines is up-regulated by hypoxia simulating in greater expression of CXCR4, CXCR2, and release of CXCL1, CXCL12, macrophage migration inhibitory factor MIF, VEGF. As a result, adhesive capacity of EPC and local tube formation are greatly improved (Kanzler et al., 2013). Thus, EPC whose recruitment from the bone marrow is stimulated by hypoxia or cytokines, serve as cellular carriers of angiogenic regulatory factors instructed to promote angiogenesis or reendothelialization. Such carrier function of EPC is compromised in aging as it was demonstrated on the reduced secretion of VEGF, IL-8, IL-17, and granulocyte-colony stimulating factor (G-CSF) from elderly human EPC (Kushner et al., 2008).

Recent data suggest that this mechanism seems to be supplemented with the complementary ones. Firstly, there is a transfer of organelles (i.e., mitochondria, lysosomes) through active tunneling nanotubes from circulating EPC [that should be very prone to initiate nanotubes activity similarly to other stem cells (Yang et al., 2016)] to the resident EC (de Cavanagh et al., 2014). Such organelle donation may rescue damaged endothelial cells from apoptosis or, conversely, facilitate active cell death and establishment of a platform for further endothelial replacement. As an example, in the senescent stressed endothelium, lysosomal transfer from EPC improves EC viability, normalizes endothelialregulated vasorelaxation, and reduces programmed cells death (Yasuda et al., 2011). Secondly, EPC-released membrane-derived microvesicles are responsible for mRNA transfer to EC. To do that, the microvesicles incorporate in EC due to intermolecular interaction of EC proteins with $\alpha 4$ and $\beta 1$ integrins (Very Late Antigen-4, VLA-4) expressed in microvesicles, thereby promoting EC proliferation, tube formation, and reducing EC apoptosis (Deregibus et al., 2007). It should be mentioned that $\alpha 4 \beta 1$ integrins are the receptors for fibronectin and VCAM-1, and the latter is important for BBB functioning in neuroinflammation (O'Carroll et al., 2015).

General population of EPC is very heterogenous and dynamic. Bone marrow hemangioblasts-derived early and late EPC might be determined in vitro being different in their ability to form new vessels and to incorporate into growing vascular networks: Late CD31(+)VE-cadherin(+)CD34(+)CD14(-)CD45(-) EPC with high expression of eNOS and VEGFR2 but not early CD31(+)VE-cadherin(-)CD34(-)CD14(+)CD45(+) EPC with low expression of eNOS and VEGFR2 (Fadini et al., 2012; Cheng et al., 2013; Minami et al., 2015). Expression of eNOS is critical for EPC proliferation and migration (Lu et al., 2015) and may contribute to controlling viability of EPC at the sites of induced angiogenesis (Dong et al., 2016). Transcriptomic data confirmed that early EPC are hematopoietic cells with monocytic phenotype and low angiogenic potential, whereas late EPC have greater proliferative potential and high expression of VEGFR2 (Medina et al., 2010) that is ultimately involved in various steps of angiogenesis and is up-regulated in EPC expansion (Smadja et al., 2007). Interestingly, differential expression of VEGFR2 and another universal EPC marker-Tie2-correlates to the ability of EPC to promote angiogenesis: high Tie2 expression is required for re-endothelialization, whereas greater number of low Tie2/high VEGFR2 cells better incorporate into CD31(+) capillaries (Adamcic et al., 2013).

Cell adhesion glycoprotein CD146 is a pan-endothelial marker found in EPC, circulating EC, and in murine brain blood vessels (Schrage et al., 2008; Flores-Nascimento et al., 2015). CD146(+) EPC belong to the group of late EPC with high pro-angiogenic potential. These EPC could be easily distinguished from CD146(+) circulating mature EC: CD146+ CD34+ CD45+ CD133+ or CD117+, and CD146+ CD34+, CD45- CD133or CD117-, respectively (Delorme et al., 2005). Moreover, proteolytically generated soluble form of this molecule (sCD146) possesses pro-angiogenic activity (Stalin et al., 2013). The exact role of CD146 expressed in cerebral endothelium remains to be evaluated, however, it takes part in the mechanism of lymphocyte extravasation through the $\mathrm{BBB}$ in neuroinflammatory conditions (Duan et al., 2013).

Some bone marrow-derived EPC express stem cells marker CD117 (c-kit) (Beaudry et al., 2007) which is involved in MMP9mediated mobilization of EPC from the bone marrow in a 
response to high concentrations of VEGF (Heissig et al., 2003), and CXCR4 which is a receptor for CXCL12 chemokine (stromal cell-derived factor-1, SDF-1) involved in the process of EPC mobilization to the peripheral blood. Bone marrow-derived and umbilical cord blood-derived EPC differ in CXCR4 expression even they demonstrate compatible angiogenic properties (Finney et al., 2006).

Increased expression of CXCR4 on EPC is required for adenosine-induced mobilization of these cells from the bone marrow (Rolland-Turner et al., 2013). The remarkable fact is that mature BMEC are also regulated by adenosine which is known as a mediator of BBB structural and functional integrity: acting at $\mathrm{A} 2 \mathrm{~A}$ adenosine receptors it increases the barrier permeability for some drugs and immune cells for the meaningful time window (Carman et al., 2011; Kim and Bynoe, 2015), therefore being suggested as a potent agent for improving drug delivery to the CNS (Gao et al., 2014). Adenosine in high concentrations is produced in various tissues from ATP by CD39/CD73 ectonucleotidases or, alternatively, via CD38 (or CD157)/CD203a/CD73 pathway sensitive to the local concentrations of $\mathrm{NAD}^{+}$(Horenstein et al., 2013). Bone marrow clonogenic niches are enriched in such enzymatic activities (Quarona et al., 2015), however, it remains to be assessed whether similar mechanism is active at NVU/BBB. At least, very recent hypothesis announced in (Panfoli et al., 2016) stated that elevated levels of adenosine in the brain and blood due to endotheliumdriven metabolism of ATP to adenosine in premature infants might be a biomarker of prematurity risk.

Circulating EC might be found in the peripheral blood due to endothelial injury, anoikis, or apoptosis. These cells express the markers of mature differentiating EC (i.e., CD31 and vWF but not CD133), and could also contribute to vascular repair (Tenreiro et al., 2016). Genomic studies revealed that expression patterns of RNAs and miRNAs in EPC and EC are different and reflect significant changes in the functional role of these two types of cells in development and maintenance of endothelium competence (Cheng et al., 2013; Chang et al., 2014).

Pericytes surrounding and supporting endothelial cells share some common properties with EPC (or with bone marrow stromal cells, BMSC): expression of adhesion molecules and VEGFR2, angiopoietin signaling, and prominent pro-angiogenic potential (Bagley et al., 2005; Winkler et al., 2014; Cantoni et al., 2015). That is not surprising due to bone marrow origin of pericytes (Lamagna and Bergers, 2006) and their potential to differentiate into various cell types or to originate from early EPC in vitro (Cantoni et al., 2015). Moreover, co-culture of EPC and bone marrow-derived stem cells in vitro (mesenchymal stem cells) results in the appearance of pericyte-like cells due to ability of bone marrow-derived stem cells to differentiate into pericytes with the paracrine regulatory activity of EPC (Loibl et al., 2014). In the context of $\mathrm{BBB}$, pericytes origin and functioning are of great importance due to higher (10-30-fold) pericyte/endothelial cell ratio in the central nervous system (CNS) comparing to other tissues (Winkler et al., 2014).

Aberrant physiology of EPC is tightly implicated in the pathogenesis of various types of pathologies associated with endothelial dysfunction and vasculopathy including diabetes mellitus, Alzheimer's disease, cerebrovascular and cardiovascular diseases etc. (Lee et al., 2010; Brea et al., 2011; Yiu and Tse, 2014; Berezin and Kremzer, 2015). Circulating CD146(+) EPC as well as BMEC have been proposed as novel biomarkers of BBB impairment in neuroinfection and neurotoxicity (Huang et al., 2013a) applicable for diagnostic purposes. At the same time, there is a growing evidence that EPC might serve as a therapeutic tool for a number of CNS pathologies including stroke, neurodevelopmental disorders, and neurodegeneration (Castillo-Melendez et al., 2013; Fukuda et al., 2013; Zhao et al., 2013). Very promising data have been obtained in the application of EPC for BBB repair in vivo (Huang et al., 2013b). However, application of EPC into routine neurological clinical practice is hampered by poor understanding the mechanisms underlying EPC homing at CNS and EPC-mediated cell-to-cell communications in cerebral microvessels within the NVU.

Migration of EPC to the BBB is dictated by numerous factors contributing to elevated permeability of $\mathrm{BBB}$ that might serve as signals for EPC mobilization and moving toward the brain tissue. Studying brain angiogenesis and BBB establishment and maturation (so-called barriergenesis) offers some unique opportunities to distinguish a role for EPC in either developmental or pathological angiogenesis since both these processes have different mechanisms and functional significance for the developing, mature and aging brain (Vallon et al., 2014). Metabolic activity of EPC and related cells with pro-angiogenic potential is not well-studied yet. There is no doubt that metabolism of EPC and metabolic microenvironment at the sites of their destination affect efficacy of angiogenesis. As an example, remodeling of primary capillary plexus and vasculogenesis during embryogenesis depend on the actual metabolic demands of the defined tissue (Yoder, 2012). Particularly, EPC metabolic activity in the resting state and upon stimulatory conditions (i.e., expansion in the bone marrow, mobilization, and targeted migration) differs. The same should be true for BMEC activated in angiogenesis and converted to tip or stalk phenotype.

Thus, it is reasonable to propose that local microenvironment in the bone marrow supporting EPC maintenance, expansion, and mobilization would have some similarities with the microenvironment providing within the NVU to support BMEC functional activity, BBB establishment and repair. Since elevated permeability of BBB is associated with the establishment of sites of active neurogenesis (Lin et al., 2015b), migration of EPC from the hematopoietic tissue to the adult $\mathrm{BBB}$ is a transfer from one clonogenic niche to another one. Upon coming to the brain microvessels, EPC incorporate in the endothelial layer or serve as a source of pro-angiogenic molecules in a way similar to pericytes and perivascular astrocytes, thereby establishing appropriate conditions for branching angiogenesis, restoration of $\mathrm{BBB}$ structural and functional integrity, and reparative neurogenesis (Figure 1).

Angiogenesis consists of cell proliferation, vessel sprouting, establishment of anastomosis, pruning and remodeling, acquisition of endothelial quiescence (Ehling et al., 2013). Antigenic and functional heterogeneity of endothelial progenitors determines the mechanisms of EPC-supported angiogenesis. In the brain, vascularization mainly occurs 

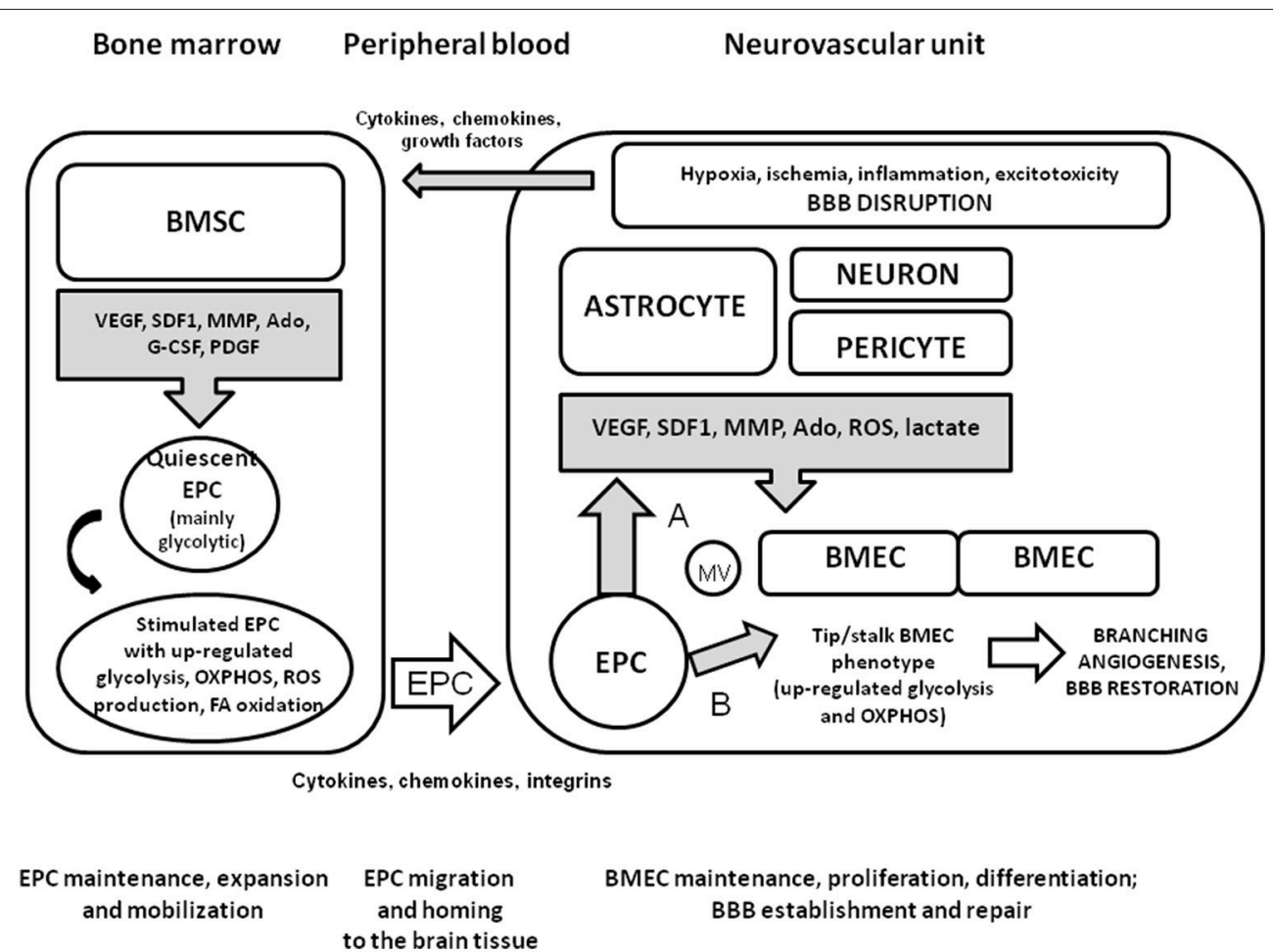

BMEC maintenance, proliferation, differentiation;

BBB establishment and repair

FIGURE 1 | Mobilization and homing of EPC to the injured brain tissue. Within the NVU, pericytes and perivascular astrocytes produce the molecules with pro-angiogenic properties upon neuronal overexcitation, hypoxic or ischemic brain injury, BBB dysfunction, or neuroinflammation. Bone marrow stromal cells secrete various factors contributing to maintenance or expansion of EPC when needed. In a quiescent state, EPC have high glycolytic activity due to relatively hypoxic micronevironment within the clonogenic niche. Being activated by cytokines, chemokines, growth factors whose systemic and local concentrations are elevated due to brain injury, EPC up-regulate metabolic pathways for effective energy production (glycolysis, mitochondrial respiration, fatty acid oxidation). Generation of ROS is enhanced as a side-effect of mitochondria activation, but is counteracted by well-established antioxidant machinery in EPC. Homing of recruited EPC to cerebral microvessels is driven by cytokine-, chemokine-, and integrin-based mechanisms. Upon arrival at the site of BBB disruption, EPC release pro-angiogenic factors and membrane vesicles enriched with EPC-specific proteins and mRNA (A); incorporate into the endothelial layer or donate organelles to the stressed EC (B). These mechanisms lead to the stimulation of branching angiogenesis associated with the activation of tip and stalk EC, and re-establishment of BBB.

through angiogenesis (Grant and Janigro, 2006), therefore different populations of cells involved into angiogenic events contribute to the initiation of vessel growth, destabilization of extracellular matrix, establishment of novel microvessels and their maturation (Figure 2). In the context of $\mathrm{BBB}$, the latter stage is corresponded to the maturation of the barrier and acquisition of adequate selective permeability and transporting activity. Presumably, all the earlier steps of angiogenesis are coupled with the elevated permeability of the BBB. Therefore, a reasonable question is how all these processes are linked to the metabolic plasticity of endothelial progenitors and other cellular components of the NVU (neurons and glia)?

\section{OXIDATIVE METABOLISM OF PROGENITOR ENDOTHELIAL CELLS AND METABOLIC STATUS OF BRAIN TISSUE: COMPLEMENTARY FEATURES}

Developmental angiogenesis and, probably, neuroplasticityassociated angiogenesis, are mainly regulated by local production of pro-angiogenic molecules (VEGF, TGF $\beta$ ) and corresponding changes in the metabolism, proliferation, and differentiation status of migrating EPC governed by Wnt/ $\beta$-catenin- and Notchsignaling (Vallon et al., 2014). In pathological angiogenesis associated with brain injury, the main stimuli provoking re-endothelialization are neuroinflammatory mediators (i.e., cytokines, growth factors) as well as hypoxia/ischemiainduced changes in the tissue metabolism that mobilize EPC from bone marrow and attract them to the brain tissue. As an example, membrane-bound Kit-ligand expressing on microvascular EC at the sites of inflammation provide effective homing of EPC to the activated endothelium (Dentelli et al., 2007).

It is reasonable to assume that neuroplasticity-associated angiogenesis might critically depend on the local branching provided by pre-existing BMEC acquiring tip or stalk phenotype, whereas developmental and pathological angiogenesis would require extensive mobilization and homing of bone marrowderived endothelial progenitors. It is still under the debates which local metabolic factors in the brain are attributed to homing of EPC to the brain and their integration into the developing cerebral microvessels, or how it is corresponded to the metabolic pattern of EPC. 


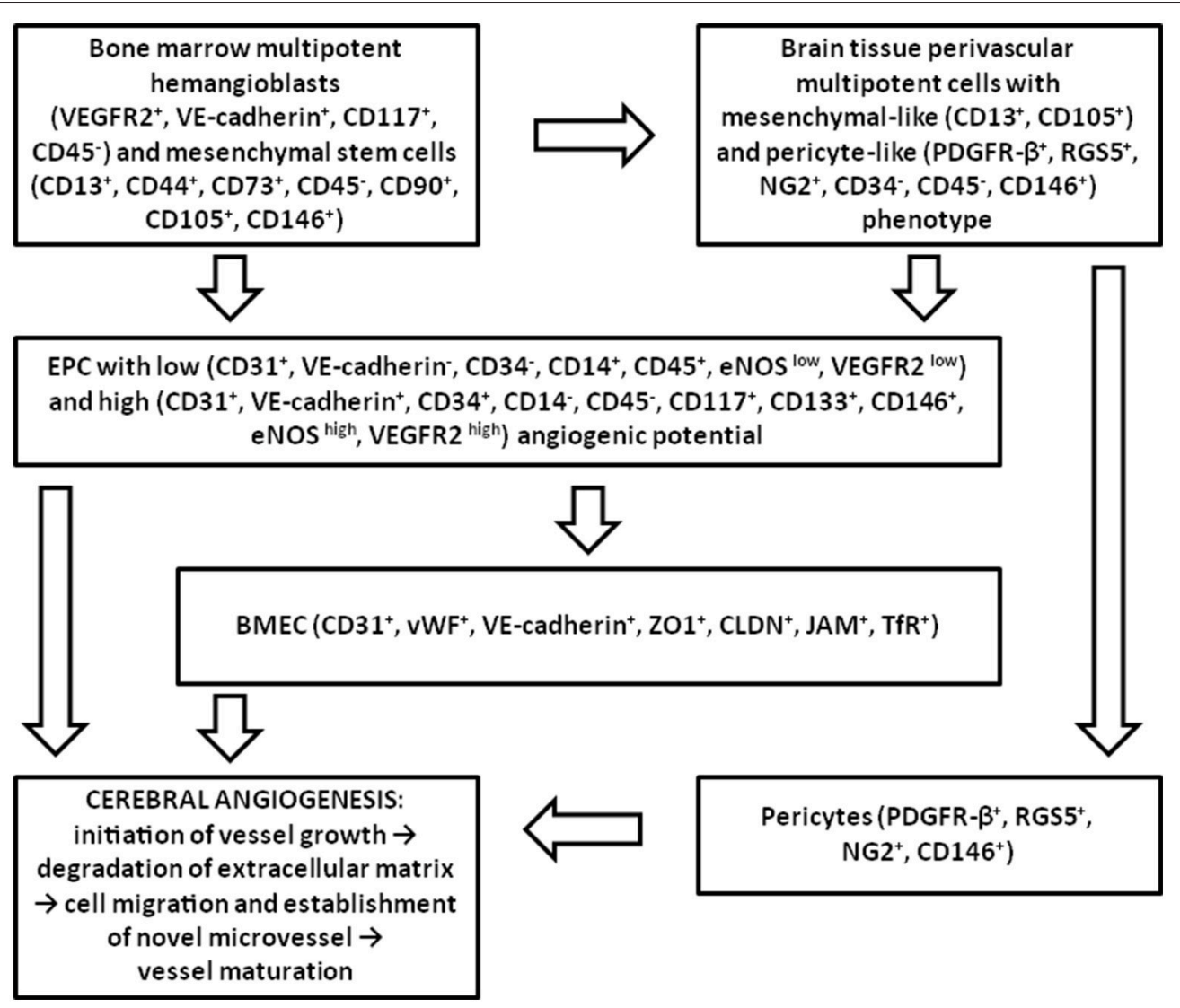

FIGURE 2 | Participation of different types of EPC in adult brain angiogenesis. In the adult brain, EPC originated from the bone marrow multipotent hemangioblasts and MSC, or from the multipotent mesenchymal-like and pericyte-like cells located in cerebral microvessels, give rise to the population of EPC which is able to activate BMEC, to integrate into the endothelial layer, and to promote recruitment and proliferation of pericytes upon the action of pro-angiogenic stimuli. Later, perivascular cells coordinate acquisition of endothelial quiescence and vessel maturation.

\section{Metabolic Plasticity of EPC}

One of the most potent local regulators of angiogenesis is hypoxia and associated metabolic events, particularly, stimulation of glycolysis. At the same time, lactate as the end-product of glycolysis has multiple functions in the brain being involved in the coordination of neuron-astrocyte metabolic coupling and gliovascular control of local blood flow (Mosienko et al., 2015; Kasparov, 2016). There is an accumulating evidence for glycolysis-mediated control of BBB development and functional activity (Salmina et al., 2015). EPC like other stem/progenitor cells are characterized by active glycolysis and high production of lactate (Goligorsky, 2014). When resident tissue BMEC acquire tip cell phenotype, glycolysis is also intensified (Stapor et al., 2014). In the BBB, expression of endothelial MCT1 transporting ketone bodies, pyruvate, and lactate is maximal in the perinatal period followed by dramatic decrease in first 1 week of postnatal life with the corresponding switch to prevailed expression of GLUT on endothelial cells and MCT1 on astroglial cells at the postweaning period in rodents (Vannucci and Simpson, 2003). Such developmental changes reflect predominant consumption of lactate and ketone bodies or glucose in fueling the developing and maturing brain, respectively. Thus, EPC migrating to cerebral microvessels in perinatal and early postnatal period appear in the microenvironment of excessive lactate and ketone bodies utilization. However, such proposal requires further assessment since recent transcriptome study has shown that MCT1 is expressed at lower levels in the embryonic choroid plexus (E15) than in the adult brain, whereas GLUT1 is expressed in an opposite manner (Saunders et al., 2013, 2015).

High-energy metabolites lactate and ketone bodies are known as promotors of stem cells or cancer cells growth and best "mitochondrial fuels" for actively-proliferating cells. To achieve such effects of lactate and ketone bodies, the target cells should express MCT1 for effective import of these metabolites and their utilization in the intracellular pathways (Curry et al., 2013). One of the possible explanations of this phenomenon was already given (Martinez-Outschoorn et al., 2011): both these metabolites increase the pool of acetyl-CoA, leading to increased histone acetylation and elevated gene expression. These authors suggested that since the brain is a particularly lactate-rich microenvironment due to lactate-producing activity of astrocytes in a close vicinity to active neurons (so-called astrocyte-neuron metabolic coupling), metastatic cancer cells may be attracted to the lactate-rich microenvironment of the brain. Similar reasoning 
shows that this might be true for EPC migrating to developing $\mathrm{BBB}$ where lactate and ketone bodies levels are rather high due to extensive expression of their transporters at the endothelial layer and great dependence of developing brain on these energy substrates. Taking into the consideration the enrichment of BBB endothelial cells with mitochondria comparing to EC in other tissues (Oldendorf et al., 1977), and obvious coupling of mitochondrial biogenesis to angiogenesis (De Bock et al., 2013), it is reasonably to propose that high expression of MCT1 in endothelial BBB cells as well as activation of astrocytic glycolysis and release of lactate at the prenatal and early postnatal period would provide the microenvironment adequate for homing and local proliferation of EPC. It is interesting that EPC as well as mature EC demonstrate the compatible rate of proliferative activity in vitro, and the number of mitochondria which is less in EPC at the beginning of cell culture is very rapidly elevated to support proliferative activity (Rae et al., 2011a).

Utilization of ketone bodies leads to elevating acetyl$\mathrm{CoA}$ and depleting NAD+ levels in the cells (Newman and Verdin, 2014). Thus, availability of NAD+ for the activity of NAD+-converting enzymes like NAD+-glycohydrolases (polyADP-ribosyl polymerase, ADP-ribosyl cyclase, monoADPribosyl transferases) or NAD+-dependent deacetylases (sirtuins) is reduced. The latter might result in higher levels of histone acetylation and maintenance of transcriptionally active chromatin in the cells.

Thus, EPC and newly-formed BMEC in the embryonic or early postnatal $\mathrm{BBB}$ might be characterized by consuming of ketone bodies and lactate, considerable mitochondrial activity, intracellular depletion of NAD+, suppression of histone deacetylation, and activation of gene transcription. In accordance with this metabolic pattern, we may propose that when $\mathrm{BBB}$ starts expression of GLUT for predominant consumption of glucose for NVU metabolic needs, glycolytic flux is activated as much as possible in BMEC, NAD+ is effectively regenerated due to pyruvate to lactate conversion, and NAD+ is easily used by NAD+-glycohydrolases or stimulates deacetylase activity. Probable involvement of NAD+-glycohydrolases (i.e., CD38) abundantly expressed in activated astroglial cells (Banerjee et al., 2008; Salmina et al., 2009) in the establishment of pro-angiogenic brain microenvironment might be suggested by analogy with the mechanism recently proposed in (Horenstein et al., 2015).

Notch signaling is one of the key regulators of oxidative cell metabolism: high proliferative potential of tumor cells corresponds to hyperactive Notch, suppression of glycolysis and preserved mitochondrial activity, whereas low proliferative potential is attributed to hypoactive Notch, suppressed glycolysis and attenuated mitochondrial respiration (Landor et al., 2011). During embryogenesis, Wnt/ $\beta$-catenin up-regulates Dll4 transcription and strongly increases Notch signaling in the endothelium, whereas excessive Notch activity results in vascular abnormalities (Corada et al., 2010). Notch signaling is a key regulator of vessel maturation and quiescence in the retinal vasculature: Dll4-Notch signaling supports the quiescent endothelial phenotype up to P28 (Ehling et al., 2013), promotes stalk phenotype of EC and results in less number of tip cells and fewer vessel branches. As expected, inhibition of Notch (i.e., with a gamma-secretase inhibitor) stimulates angiogenesis (Hellström et al., 2007). In endothelial cells, diminished Notch activity due to sirtuin-mediated deacetylation results in excessive vessel branching (Guarani et al., 2011). Whether analogous mechanism is true for EPC remains to be assessed but some data might confirm this proposal: Proteomic and functional analysis has revealed that Notch signaling is required for EPC functioning and angiogenesis (Karcher et al., 2015), but slight reduction of Notch signaling promotes EPC activity and reduces EPC apoptosis (Ii et al., 2010). Presumably, this bidirectional effect is linked to EPC heterogeneity: Notch signaling regulates EPC functions differentially in early (stimulation of cell proliferation, migration) and late-more matured-EPC (suppression of cell proliferation, migration, and vessel sprouting) (Chen et al., 2012).

In actively proliferating cells, Wnt-signaling serves as a positive regulator of glycolysis (Pate et al., 2014). It should be mentioned that activation of $\mathrm{Wnt} / \beta$-catenin signaling pathway in mature brain endothelial cells results in up-regulation of MCT1 expression, whereas inhibition of gamma-secretase and corresponding suppression of Notch signaling reduces Wnt $/ \beta$ catenin effects on MCT1 expression (Liu et al., 2016). So, MCT1 expression in BMEC critically depends on Wnt $/ \beta$-cateninand Notch-signaling, and the same is true for GLUT1 and claudin-5 expression in the BBB (Vallon et al., 2014). Among other regulators of MCT1 in BMEC are cAMP-generating intracellular signaling pathways (cAMP induces phosphorylation and internalization of MCT1 proteins) (Smith et al., 2012) and intracellular $\mathrm{pH}$ (acidic $\mathrm{pH}$ inhibits while alkaline $\mathrm{pH}$ activates MCT1 activity) (Uhernik et al., 2011). The same Wnt-signaling pathway is critical for the generation of EPC from pluripotent stem cells (Lian et al., 2014) that might be under the control of oxygen availability and HIF-1 activity in undifferentiated cells: low oxygen concentrations in clonogenic niches result in the stabilization of HIF-1 followed by the activation of Wntsignaling (Mazumdar et al., 2010; De Miguel et al., 2015). Thus, it is not surprising that next step in the development of EPC into EC is controlled by Wnt-signaling as well: over-expression of HIF-1 in EPC promotes EPC proliferation, migration, and differentiation to EC with clearly distinguishable endothelial phenotype CD31(+)VEGFR2(+)eNOS(+) (Jiang et al., 2008). Therefore, high proliferative and pro-angiogenic potential of EPC is equivalent to high HIF-1 activity (due to relative oxygen deficits in clonogenic niches either in bone marrow or in the developing brain), activated Wnt-signaling, and prominent MCT1 expression in these cells.

Actually, this mechanism seems to be very similar to the socalled "reverse Warburg effect" proposed for some tumor cells. It is well-known that Warburg effect is driven by the modulation of Wnt-signaling: suppression of Wnt leads to reduced glycolytic flux, and MCT1 appears to be one of the targets (Pate et al., 2014). This mechanism helps the cells to direct pyruvate from TCA to LDH-mediated conversion to lactate followed by its release from the cells. Similar mechanism has been proposed as a basis for tumor-directed establishment of microenvironment supporting tumor growth. According to this idea, tumor cells make the surrounding stromal or endothelial cells more glycolytic via stabilization of HIF-1 for effective generation of lactate (and, 
probably, ketones and pyruvate) and its export for feeding the tumor cells equipped with MCT1. The same effect has been attributed to the mechanisms of tumor neoangiogenesis: Tumor cells stimulate endothelial cell migration, tube formation, and tumor angiogenesis through the induction of HIF-1 in endothelial cells (Doherty and Cleveland, 2013) due to HIF-1 $\alpha$ stabilizing activity of released lactate (De Saedeleer et al., 2012). In the developing BBB, the main source of lactate is astroglia surrounding endothelial layer (Salmina et al., 2015), therefore establishment of high local concentrations of lactate may provide the microenvironment optimal for EPC migration and EPC differentiation toward BMEC. Taking into the consideration the stimulatory effect of lactate on EPC mobilization in vitro (Milovanova et al., 2008a), we may assume that high local lactate concentrations established in bone marrow or in the perivascular space of BBB are the prerequisite for effective participation of $\mathrm{EPC}$ in brain angiogenesis.

Release and utilization of lactate is coordinated by MCT expression which is a target for CD147-mediated control. CD147 (extracellular matrix metalloproteinase inducer EMMPRIN, or basigin) is one of the well-known inducers of angiogenesis contributing to the following processes: (i) lactate utilization in the cells due to action of CD147 as a chaperone for MCT1 and MCT4 lactate transporters to facilitate their membrane expression; (ii) glucose uptake through CD147 interaction with GLUT1; (iii) amino acid transmembrane transport due to functional association of CD147 with CD98 (Xu and Hemler, 2005; Muramatsu, 2016). Role of CD147 in angiogenesis is further confirmed by its interactions and stimulatory action on MMP and VEGFR2 (Bougatef et al., 2009) that might have an importance for the recruitment of responding subpopulation from the bone marrow (Chen et al., 2015). It was recently shown that cyclophilin A which is one of CD147 ligands in various tissues acts on CD117 (c-kit)-immunopositive bone-marrow progenitors, thereby contributing to angiogenesis (Perrucci et al., 2016). Proteomic analysis of EPC revealed expression of CD147 protein (Kaczorowski et al., 2013). On other hand, CD147 is highly expressed in the capillary endothelium in the CNS being known as neurothelin for a long time (Kaushik et al., 2015). Moreover, it was proposed as an earliest molecular marker for endothelial cells that will form the blood-brain barrier (Schlosshauer and Herzog, 1990) whose expression is positively regulated by neighboring astroglia (Janzer et al., 1993). This may seem paradoxical that recent "renaissance" in CD147 studies mainly relates to tumor cells oxidative metabolism or tumorinduced angiogenesis, but not to the role of CD147 in the BBB. In sum, it is evidently necessary to assess whether CD147 expressed in EPC and BMEC might serve as a regulator of local proangiogenic microenvironment within the bone marrow and the BBB.

A shift in perspective is needed when we are talking about biological role of glycolysis in progenitor cells. It is clear that glycolytic activity determines not only lactic acid production but is also responsible for maintaining $\mathrm{NAD}+/ \mathrm{NADH}$ ratio due to pyruvate-lactate conversion at the final step of the process. According to this view, NAD+ regeneration at this stage contributes to intracellular NAD + pool, thereby providing indirect regulatory action on $\mathrm{NAD}+$-consuming (i.e., $\mathrm{NAD+}$-glycohydrolases) and NAD+-dependent (i.e., sirtuins) mechanisms (Salmina et al., 2012).

Stem and progenitor cells seem to be critically depended on $\mathrm{NAD}+$ levels, and NAD+ deficit results in loss of self-renewal capacity or impairment of differentiation. Many metabolic processes are very sensitive to changes in NAD+ bioavailability, i.e., chromatin acetylation/deacetylation, oxidative metabolism, intracellular calcium mobilization, and calcium-dependent processes (migration, adhesion, programmed cell death etc.). We may apply those considerations to some of the mechanisms linking NAD+ and functional activity of EPC as shown below.

\section{NAD+ Levels and Progenitor Cells Functioning}

Mobilization of EPC from the bone marrow in vivo, their migration, proliferation and angiogenic activity in vitro can be inhibited by suppressing the activity of nicotinamide phosphoribosyltransferase (NAMPT) which is the key enzyme for NAD+ synthesis, whereas overexpression of NAMPT led to a SIRT1-depedent enhancement of Notch-1 intracellular domain (NICD) deacetylation, inhibition of Notch signaling, up-regulation of VEGFR2 and VEGFR3 expression, and neovascularization (Wang et al., 2014). Depletion of intracellular NAD+ levels is associated with EPC impairment in diabetic patients, whereas restoring NAD+ pool rescued EPC mobilization due to stromal cell-derived factor-1 $\alpha$ (SDF$1 \alpha$ )-mediated events and eNOS expression in EPC (Wang et al., 2016). So, it is quite clear that effective angiogenesis requires high intracellular NAD+ levels in EPC and, presumably, in BMEC. However, very recent data suggest that in some tissues, NAD+ synthesis might be positively regulated by the proliferator-activated receptor gamma coactivator- $1 \alpha$ (PGC-1 $\alpha$ ) (Tran et al., 2016). At the same time, PGC-1 $\alpha$ is a well-described regulator of mitochondrial biogenesis due to activation of PPAR $\gamma$ and a wide spectrum of transcription factors. In a case of angiogenesis demand, EPC in the peripheral blood as well as endothelial cells in tissue elevate expression of PGC- $1 \alpha$ resulting in the activation of Notch signaling and suppression of EPC migration, inhibition of angiogenesis and re-endothelialization (Sawada et al., 2014). Nevertheless, there is no contradiction here, because intracellular NAD+ levels represent very labile and compartment-specific parameter. Therefore, it is reasonably that dynamic changes in NAD+ bioavailability due to glycolytic flux, mitochondrial activity and utilization of NAD+ as a substrate for enzymatic conversion differentially affect SIRT1/Notch-machinery in EPC. In addition, as we discussed above, NAD+-sensitive pathways (i.e., local production of adenosine in the bone marrow or, presumably, at the $\mathrm{BBB}$ ) might contribute to the regulation of EPC fate and BMEC activity.

\section{NAD+ Levels and Progenitor Cells Senescence}

Stem/progenitor cells in general, and EPC, particularly, undergo process of cellular senescence being subjected to 
inappropriate conditions triggering accumulation of genetic defects, inactivation of telomerase activity, pro-apoptotic changes, depletion of total and mitochondrial NAD + pools, whereas restoration of $\mathrm{NAD}+$ levels postpones senescenceassociated changes (Zhu et al., 2006; Kushner et al., 2011; Son et al., 2016; Zhang et al., 2016).

AMP-activated protein kinase (AMPK) appears to be a good candidate for linking oxidative metabolism and NAD+ levels in EPC. Upon activation, AMPK promotes ATP-generating processes (i.e., glycolysis, fatty acid oxidation) and inhibits ATP-consuming processes (i.e., biosynthesis). In general, AMPK activity results in elevating the intracellular NAD+ levels (Cantó et al., 2009). In relation to foregoing effects of CD147 on EPC, we should mention that AMPK activity is in the tight functional connection with CD147-CD98hc complex in actively proliferating epithelial cells: loosening CD147-CD98hc complex leads to the suppression of cell proliferation and activation of AMPK (Xu and Hemler, 2005).

Recent data reveal pro-angiogenic effect of AMPK activator cilostazol either in EPC or EC (Tseng et al., 2016). It is interesting to mention that activation of AMPK and sirtuin 1 might be also achieved by the anti-diabetic drug metformin, caloric restriction, physical exercise, or resveratrol. The latter one induces NAD+- and PGC-1 $\alpha$-dependent enhancement of mitochondrial function and mitochondrial biogenesis in muscle cells (Price et al., 2012). Experimental data suggest that this AMPKrelated mechanism might be, at least partially, responsible for well-known numerous positive effects of resveratrol on EPC proliferation, differentiation, their contribution to angiogenesis, and prevention of cellular senescence due to telomerase activation (Wang et al., 2007; Xia et al., 2008; Campagnolo et al., 2015), pro-reparative effect of physical exercise on EPC mobilization (Kazmierski et al., 2015), and metformininduced normalization of EPC differentiation (Li et al., 2015a). Related mechanism seems to be actual for EC derived from induced pluripotent stem cells (Jiang et al., 2015). In the context of $\mathrm{BBB}$, overexpression of $\mathrm{AMPK}$ in $\mathrm{BMEC}$ preserves the structural and functional integrity of the barrier in neuroinfection (Zhao et al., 2014). The same is true for the effect of resveratrol on $\mathrm{BBB}$ in neuroinflammation in vitro (Hu and Liu, 2016), or for the effect of metformin on $\mathrm{BBB}$ in ischemic brain in vivo (Liu et al., 2014). But it remains unclear how AMPK activity might contribute to EPC homing at CNS, and barriergenesis. Moreover, in the more complicated multicellular systems, effects of AMPK activators might be quite different as it follows from the recent data on both positive and negative (time of application-dependent) effects of AMPK activation on neuronal survival in neonatal hypoxic-ischemic brain injury (Rousset et al., 2015) This finding emphasizes the importance of evaluating the presumable neuroprotective activity of any drug-candidate in ontogenetic aspect and in the context of cell-to-cell communications within the NVU.

Table 1 summarizes general metabolic characteristics of EPC in comparison to EC and BMEC.

\section{MICROPHYSIOLOGICAL SYSTEMS AND MICROFLUIDICS-BASED BBB MODELS IN VITRO: APPLICATION OF EPC}

Development of relevant blood-brain models in vitro is one of the topic problems in modern neurobiology and neuropharmacology. The "ideal" model should match the following criteria: (i) combination of minimally required cell types critical for structural and functional $\mathrm{BBB}$ integrity; (ii) reconstruction of the key mechanisms responsible for selective permeability of the $\mathrm{BBB}$; (iii) long-term preservation of functional and structural integrity during the model culturing in vitro; (iv) reproduction of specific properties of the defined cell population within the model in (patho)physiological conditions; (v) relative simplicity of assembling the barrier and assessment of its permeability.

Among all the approaches proposed to achieve the abovementioned goals, using the stem cell-derived components of the $\mathrm{BBB}$ in the models in vitro appears as very promising solution, particularly, for some special tasks (i.e., modeling the developing $\mathrm{BBB}$, assessment of $\mathrm{BBB}$ permeability corresponding to the neonatal period etc.). This direction is further actualized while thinking about microphysiological systems reflecting basic properties of biological tissues and organs in the miniature scale.

It is now possible to see the increasing significance of the knowledge of EPC contribution to BBB development and functioning in the context of microphysiological systems (MPS). MPS are the complex in vitro models of tissues and organs (combination of so-called "organoids") aimed to establish their functional interrelations. In most the cases, it is the next step after the application of microfluidic technologies to the reconstruction of "organ-on-chip" or "body-on-chip" in the microenvironment close to the real one. Moreover, "physiome-on-chip" concept (Stokes et al., 2015) could be more beneficial in obtaining relevant physiological data using MPS approach.

It should be mentioned that microfluidics has influenced $\mathrm{BBB}$ modeling in vitro a lot: several successful attempts to establish functional $\mathrm{BBB}$ on the microfluidic platform have been reported (Booth and Kim, 2012; Griep et al., 2013; Cho et al., 2015). At the same time, there is also increasing interest in the utilization of stem cells-derived material for BBB constructing in vitro: development of astrocytes and neurons from neural progenitor cells (Lippmann et al., 2011; Khilazheva et al., 2015), development of BMEC from induced pluripotent stem cells (Lippmann et al., 2012), or even establishment of the barrier from BMEC and neural stem cells in vitro (Chou et al., 2014).

Complementary properties of both these approaches will make possible the reconstruction of stem cells-derived cell components of NVU/BBB in the improved microenvironment like it was recently suggested for "brain-on-chip" technologies (Alcendor et al., 2013; van der Helm et al., 2016) applicable for effective in vitro drug screening. In this context, reconstruction of brain microvasculature in a flow-directed MPS is one of the topic question which might be solved using EPC as not only a source of BMEC, but also as informative monitoring system to study angiogenesis/barriergenesis “on-line.” 
TABLE 1 | Key metabolic properties of EPC, EC/BMEC.

\begin{tabular}{|c|c|c|}
\hline & EPC & EC, BMEC \\
\hline Basal glycolytic rate and lactate production & High & High, particularly in phalanx and stalk cells \\
\hline $\begin{array}{l}\text { Glycolytic rate and lactate production upon stimulatory } \\
\text { conditions (expansion, mobilization, migration) }\end{array}$ & Elevated (not more than 2-fold) & $\begin{array}{l}\text { Elevated in tip and stalk cells, suppressed when } \\
\text { branching is reduced }\end{array}$ \\
\hline Mitochondrial number and OXPHOS intensity & $\begin{array}{l}\text { Low mitochondrial mass, immature } \\
\text { mitochondrial morphology; low OXPHOS }\end{array}$ & $\begin{array}{l}\text { High mitochondrial mass in BMEC comparing to EC in } \\
\text { other tissues; OXPHOS is less notable than glycolysis }\end{array}$ \\
\hline $\begin{array}{l}\text { Mitochondrial number and OXPHOS intensity upon } \\
\text { stimulatory conditions (expansion, mobilization, } \\
\text { migration) }\end{array}$ & Up-regulated & Up-regulated \\
\hline $\begin{array}{l}\text { Mitochondrial ROS production upon basal and } \\
\text { stimulatory conditions (expansion, mobilization, } \\
\text { migration) }\end{array}$ & $\begin{array}{l}\text { Up-regulated upon EPC stimulation but the } \\
\text { antioxidant activity is high }\end{array}$ & $\begin{array}{l}\text { Low in quiescent cells but up-regulated in branching } \\
\text { angiogenesis }\end{array}$ \\
\hline Utilization of ketone bodies & High & High at the earliest stages of ontogenesis \\
\hline Fatty acid oxidation & Relatively low, elevated in stimulatory conditions & High, particularly in low glucose conditions \\
\hline Pentose phosphate pathways activity & Low & High \\
\hline Lactate-mediated effects & Stimulates migration and differentiation & Stimulates angiogenesis \\
\hline Physiological and biochemical heterogeneity & High & Low \\
\hline
\end{tabular}

Based on the integrated data presented in Oldendorf et al., 1977; Dernbach et al., 2004; Milovanova et al., 2008b; Fraisl et al., 2009; Freeman and Keller, 2012; De Bock et al., 2013; Goligorsky, 2014; Harjes et al., 2014; Tang et al., 2014; Xu et al., 2014; Salmina et al., 2015; Schoors et al., 2015.

So, what are the possible advantages in the application of EPC for NVU/BBB modeling in vitro and MPS designing? Establishment of vessel networks at the microfluidic platform and in MPS is performed by seeding EC (usually HUVEC, or BMEC if BBB model is reconstructing) as well as accessory cells, (i.e., pericytes or astrocytes) within the chamber channels. To provide efficient endothelial proliferation and vessel sprouting, chemical gradient of pro-angiogenic factors (i.e., VEGF) can be settled in the close vicinity to the growing vessel (Sakolish et al., 2016). Dynamic fluid flow mimics the conditions achieved in the real $\mathrm{BBB}$ and allows controlling in vivo-like vessel barriergenesis. In a case of BMEC, BBB-specific phenotype of the cells is one of the critical factors for proper modeling the barrier or its functional connection with other tissues/organoids within the MPS (Alcendor et al., 2013). Therefore, the following physiological and metabolic parameters of EPC or BMEC should be taken into the consideration in BBB models or MPS: (i) ability to establish functionally competent monolayer with BBB-specific properties (selective permeability, tight junction connections, expression of specific receptors and transporters) reproducible in either static or microfluidic conditions; (ii) high sensitivity to the action of pro-angiogenic stimuli (VEGF, MMP, lactate etc.) produced by surrounding cells; (iii) dynamic changes in cell metabolism upon action of glia-, pericyte-, or neuron-derived signals; (iv) ontogenesis-related changes in cell metabolism; (v) expression of molecules critical for CNS homing and acquisition of BBB-specific phenotype; (vi) ability to support neurogenesis within the neurogenic niches in vitro.

Translational prospects of $\mathrm{BBB}$ models in vitro or BBBon-chip technologies dictate the urgent interest in selecting the most appropriate EC whose growth and functional activity would be relevant for in vitro testing and drug candidates and assessment of BBB disruption in various CNS disorders. Thus, application of EPC would be beneficial for the controlled growth of brain microvessel-like structures in the conditions close to the
BBB microenvironment in order to facilitate further studies of NVU/BBB or cerebrovascular (patho)physiology (Cucullo et al., 2013), particularly, at early stages of ontogenesis. Also, EPC would overcome the problem of human brain microvascular cells availability for BBB modeling or MPS in vitro. Currently, few BBB models in vitro utilize human endothelial cells, and this problem hampers progress in preclinical pharmacological studies (Pamies et al., 2014). Human induced pluripotent stem cells are tested as a source of NVU components not only in the static BBB models (Lippmann et al., 2012) but also for the microfluidics-based technological solutions (Brown et al., 2015). Microfluidic approach might be also used for specific and efficient capture of EPC from the peripheral blood as it was demonstrated in cardiovascular bioengineering (Plouffe et al., 2009; Lin et al., 2015a). Then, development of "user friendly" protocols for in vitro differentiation of EPC obtained from the bone marrow or peripheral blood into BMEC, and for the establishment of NVU microenvironment supporting EPC integration in the growing microvessels would give us an opportunity to establish fully functioning endothelial layer with $\mathrm{BBB}$ characteristics. Solving these technological questions would provide novel engineering approaches toward controlling brain developmental and pathological angiogenesis, improved microfluidically-supported BBB models and/or brain multicompartment MPS suitable for translational studies in neurology and neuropharmacology.

\section{CONCLUSION}

Metabolic and functional plasticity of EPC controls their timely recruitment, precise homing to the brain microvessels, and efficient support of brain angiogenesis. Being under the control of numerous regulatory factors, EPC serve as a source of BMEC with $\mathrm{BBB}$ specific characteristics in the developing brain. In the 
adult brain, EPC contribute (directly or as a source and carrier of pro-angiogenic factors) to BBB re-endothelialization upon injury or to the cerebral angiogenesis associated with physiological conditions (i.e., activity-induced neurogenesis) or pathological conditions (i.e., tumor progression). A key challenge in the field of EPC physiology is the current shortage of the knowledge on the most efficient ways to manipulating their activity both in vitro and in vivo. However, solving this problem would be beneficial for the therapy of cerebrovascular diseases, brain trauma, neurodegeneration, brain tumors, and neuroinfection. Metabolic activity and functionality of EPC differs from those of BMEC and is tightly regulated by numerous systemic and local factors at all the steps of EPC development. Accumulating evidence suggests that further progress in studying BBB (patho)physiology, establishment of new therapeutic methods for reversible and controlled $\mathrm{BBB}$ opening, or designing the new in vitro assays for drug development (BBB models or microphysiological constructions) critically depends on deciphering molecular and biochemical mechanisms underlying EPC functional role in

\section{REFERENCES}

Adamcic, U., Yurkiewich, A., and Coomber, B. L. (2013). Differential expression of Tie2 receptor and VEGFR2 by endothelial clones derived from isolated bovine mononuclear cells. PLoS ONE 7:e53385. doi: 10.1371/journal.pone.0053385

Alcendor, D. J., Block, F. E. III., Cliffel, D. E., Daniels, J. S., Ellacott, K. L., Goodwin, C. R., et al. (2013). Neurovascular unit on a chip: implications for translational applications. Stem Cell Res. Ther. 4(Suppl. 1), S18. doi: 10.1186/scrt379

Arai, K., Jin, G., Navaratna, D., and Lo, E. H. (2009). Brain angiogenesis in developmental and pathological processes: neurovascular injury and angiogenic recovery after stroke. FEBS J. 276, 4644-4652. doi: 10.1111/j.17424658.2009.07176.x

Azmitia, E. C., Saccomano, Z. T., Alzoobaee, M. F., Boldrini, M., and WhitakerAzmitia, P. M. (2016). Persistent angiogenesis in the autism brain: an immunocytochemical study of postmortem cortex, brainstem and cerebellum. J. Autism Dev. Disord. 46, 1307-1318. doi: 10.1007/s10803-015-2672-6

Bagley, R. G., Weber, W., Rouleau, C., and Teicher, B. A. (2005). Pericytes and endothelial precursor cells: cellular interactions and contributions to malignancy. Cancer Res. 65, 9741-9750. doi: 10.1158/0008-5472.can-04-4337

Balaji, S., King, A., Crombleholme, T. M., and Keswani, S. G. (2013). The role of endothelial progenitor cells in postnatal vasculogenesis: implications for therapeutic neovascularization and wound healing. Adv. Wound Care 2, 283-295. doi: 10.1089/wound.2012.0398

Banerjee, S., Walseth, T. F., Borgmann, K., Wu, L., Bidasee, K. R., Kannan, M. S., et al. (2008). CD38/cyclic ADP-ribose regulates astrocyte calcium signaling: implications for neuroinflammation and HIV-1-associated dementia. J. Neuroimmune Pharmacol. 3, 154-164. doi: 10.1007/s11481-008-9105-7

Beaudry, P., Hida, Y., Udagawa, T., Alwayn, I. P., Greene, A. K., Arsenault, D., et al. (2007). Endothelial progenitor cells contribute to accelerated liver regeneration. J. Pediatr. Surg. 42, 1190-1198. doi: 10.1016/j.jpedsurg.2007.02.034

Berezin, A. E., and Kremzer, A. A. (2015). Content of circulating endothelial progenitor cells in patients with chronic ischemic heart failure with preserved left ventricular ejection fraction. Kardiologiia 55, 14-22. doi: 10.18565/cardio. 2015

Biron, K. E., Dickstein, D. L., Gopaul, R., and Jefferies, W. A. (2011). Amyloid triggers extensive cerebral angiogenesis causing blood brain barrier permeability and hypervascularity in Alzheimer's Disease. PLoS ONE 6:e23789. doi: 10.1371/journal.pone.0023789

Boldrini, M., Hen, R., Underwood, M. D., Rosoklija, G. B., Dwork, A. J., Mann, J. J., et al. (2012). Hippocampal angiogenesis and progenitor cell proliferation are increased with antidepressant use in major depression. Biol. Psychiatry 72, 562-571. doi: 10.1016/j.biopsych.2012.04.024 the developmental, pathological, and plasticity-driven cerebral angiogenesis.

\section{AUTHOR CONTRIBUTIONS}

NM Drafting the work for important intellectual content; YK Substantial contributions to the conception or design of the work; VS Final approval of the version to be published; AM Drafting the work for important intellectual content; ANS Substantial contributions to the conception or design of the work; YP Substantial contributions to the conception or design of the work; EB Drafting the work for important intellectual content; ABS Substantial contributions to the conception or design of the work, final approval of the version to be published.

\section{ACKNOWLEDGMENTS}

The study is supported by a grant given by the Russian Science Foundation (project N 14-25-00054).

Booth, R., and Kim, H. (2012). Characterization of a microfluidic in vitro model of the blood-brain barrier (muBBB). Lab Chip 12, 1784-1792. doi: 10.1039/ c2lc40094d

Bougatef, F., Quemener, C., Kellouche, S., Naïmi, B., Podgorniak, M. P., Millot, G., et al. (2009). EMMPRIN promotes angiogenesis through hypoxia-inducible factor-2alpha-mediated regulation of soluble VEGF isoforms and their receptor VEGFR-2. Blood 114, 5547-5556. doi: 10.1182/blood-2009-04-217380

Boxall, S. A., and Jones, E. (2012). Markers for characterization of bone marrow multipotential stromal cells. Stem Cells Int. 2012, 12. doi: 10.1155/2012/975871

Brea, D., Rodríguez-González, R., Sobrino, T., Rodríguez-Yañez, M., Blanco, M., and Castillo, J. (2011). Proteomic analysis shows differential protein expression in endothelial progenitor cells between healthy subjects and ischemic stroke patients. Neurol. Res. 33, 1057-1063. doi: 10.1179/1743132811y.0000000038

Brown, J. A., Pensabene, V., Markov, D. A., Allwardt, V., Neely, M. D., Shi, M., et al. (2015). Recreating blood-brain barrier physiology and structure on chip: a novel neurovascular microfluidic bioreactor. Biomicrofluidics 9, 054124. doi: 10 . 1063/1.4934713

Caiado, F., Carvalho, T., Silva, F., Castro, C., Clode, N., Dye, J. F., et al. (2011). The role of fibrin $\mathrm{E}$ on the modulation of endothelial progenitors adhesion, differentiation and angiogenic growth factor production and the promotion of wound healing. Biomaterials 32, 7096-7105. doi: 10.1016/j.biomaterials.2011. 06.022

Campagnolo, P., Hong, X., di Bernardini, E., Smyrnias, I., Hu, Y., and Xu, Q. (2015). Resveratrol-induced vascular progenitor differentiation towards endothelial lineage via MiR-21/Akt/ $\beta$-catenin is protective in vessel graft models. PLoS ONE 10:e0125122. doi: 10.1371/journal.pone.0125122

Cantó, C., Gerhart-Hines, Z., Feige, J. N., Lagouge, M., Noriega, L., Milne, J. C., et al. (2009). AMPK regulates energy expenditure by modulating NAD+ metabolism and SIRT1 activity. Nature 458, 1056-1060. doi: 10.1038/ nature 07813

Cantoni, S., Bianchi, F., Galletti, M., Olivi, E., Alviano, F., Galiè, N., et al. (2015). Occurring of in vitro functional vasculogenic pericytes from human circulating early endothelial precursor cell culture. Stem Cells Int. 2015:943671. doi: 10. $1155 / 2015 / 943671$

Carman, A. J., Mills, J. H., Krenz, A., Kim, D. G., and Bynoe, M. S. (2011). Adenosine receptor signaling modulates permeability of the bloodbrain barrier. J. Neurosci. 31, 13272-13280. doi: 10.1523/jneurosci.333711.2011

Castillo-Melendez, M., Yawno, T., Jenkin, G., and Miller, S. L. (2013). Stem cell therapy to protect and repair the developing brain: a review of mechanisms of action of cord blood and amnion epithelial derived cells. Front. Neurosci. 7:194. doi: $10.3389 /$ fnins.2013.00194 
Chang, T. Y., Huang, T. S., Wang, H. W., Chang, S. J., Lo, H. H., Chiu, Y. L., et al. (2014). miRNome traits analysis on endothelial lineage cells discloses biomarker potential circulating microRNAs which affect progenitor activities. BMC Genomics 15:802. doi: 10.1186/1471-2164-15-802

Chao, H., and Hirschi, K. K. (2010). Hemato-vascular origins of endothelial progenitor cells? Microvasc. Res. 79, 169-173. doi: 10.1016/j.mvr.2010.02.003

Chen, J. Y., Feng, L., Zhang, H. L., Li, J. C., Yang, X. W., Cao, X. L., et al. (2012). Differential regulation of bone marrow-derived endothelial progenitor cells and endothelial outgrowth cells by the notch signaling pathway. PLoS ONE 7:e43643. doi: 10.1371/journal.pone.0043643

Chen, Y., Gou, X., Kong, D. K., Wang, X., Wang, J., Chen, Z., et al. (2015). EMMPRIN regulates tumor growth and metastasis by recruiting bone marrowderived cells through paracrine signaling of SDF-1 and VEGF. Oncotarget 6, 32575-32585. doi: 10.18632/oncotarget.5331

Cheng, C. C., Chang, S. J., Chueh, Y. N., Huang, T. S., Huang, P. H., Cheng, S. M., et al. (2013). Distinct angiogenesis roles and surface markers of early and late endothelial progenitor cells revealed by functional group analyses. BMC Genomics 14:182. doi: 10.1186/1471-2164-14-182

Cho, H., Seo, J. H., Wong, K. H., Terasaki, Y., Park, J., Bong, K., et al. (2015). Three-dimensional blood-brain barrier model for in vitro studies of neurovascular pathology. Sci. Rep. 5:15222. doi: 10.1038/srep 15222

Chou, C. H., Sinden, J. D., Couraud, P. O., and Modo, M. (2014). In vitro modeling of the neurovascular environment by coculturing adult human brain endothelial cells with human neural stem cells. PLOS ONE 9:e106346. doi: 10. 1371/journal.pone.0106346

Corada, M., Nyqvist, D., Orsenigo, F., Caprini, A., Giampietro, C., Taketo, M. M., et al. (2010). The Wnt/beta-catenin pathway modulates vascular remodeling and specification by upregulating Dll4/Notch signaling. Dev. Cell 18, 938-949. doi: 10.1016/j.devcel.2010.05.006

Coşkun, S., Chao, H., Vasavada, H., Heydari, K., Gonzales, N., Zhou, X., et al. (2014). Development of the fetal bone marrow niche and regulation of HSC quiescence and homing ability by emerging osteolineage cells. Cell Rep. 9, 581-590. doi: 10.1016/j.celrep.2014.09.013

Cucullo, L., Hossain, M., Tierney, W., and Janigro, D. (2013). A new dynamic in vitro modular capillaries-venules modular system: cerebrovascular physiology in a box. BMC Neurosci. 14:18. doi: 10.1186/1471-2202-14-18

Curry, J. M., Tuluc, M., Whitaker-Menezes, D., Ames, J. A., Anantharaman, A., Butera, A., et al. (2013). Cancer metabolism, stemness and tumor recurrence: MCT1 and MCT4 are functional biomarkers of metabolic symbiosis in head and neck cancer. Cell Cycle 12, 1371-1384. doi: 10.4161/cc. 24092

De Bock, K., Georgiadou, M., and Carmeliet, P. (2013). Role of endothelial cell metabolism in vessel sprouting. Cell Metab. 18, 634-647. doi: 10.1016/j.cmet. 2013.08.001

de Cavanagh, E. M., González, S. A., Inserra, F., Forcada, P., Castellaro, C., Chiabaut-Svane, J., et al. (2014). Sympathetic predominance is associated with impaired endothelial progenitor cells and tunneling nanotubes in controlledhypertensive patients. Am. J. Physiol. Heart Circ. Physiol. 307, H207-H215. doi: 10.1152/ajpheart.00955.2013

De Miguel, M. P., Alcaina, Y., de la Maza, D. S., and Lopez-Iglesias, P. (2015). Cell metabolism under microenvironmental low oxygen tension levels in stemness, proliferation and pluripotency. Curr. Mol. Med. 15, 343-359. doi: 10.2174/ 1566524015666150505160406

De Saedeleer, C. J., Copetti, T., Porporato, P. E., Verrax, J., Feron, O., and Sonveaux, P. (2012). Lactate activates HIF-1 in oxidative but not in Warburgphenotype human tumor cells. PLOS ONE 7:e46571. doi: 10.1371/journal.pone. 0046571

Delorme, B., Basire, A., Gentile, C., Sabatier, F., Monsonis, F., Desouches, C., et al. (2005). Presence of endothelial progenitor cells, distinct from mature endothelial cells, within human CD146+ blood cells. Thromb. Haemost. 94, 1270-1279. doi: 10.1160/th05-07-0499

Dentelli, P., Rosso, A., Balsamo, A., Colmenares Benedetto, S., Zeoli, A., Pegoraro, M., et al. (2007). C-KIT, by interacting with the membrane-bound ligand, recruits endothelial progenitor cells to inflamed endothelium. Blood 109, 4264-4271. doi: 10.1182/blood-2006-06-029603

Deregibus, M. C., Cantaluppi, V., Calogero, R., Lo Iacono, M., Tetta, C., Biancone, L., et al. (2007). Endothelial progenitor cell-derived microvesicles activate an angiogenic program in endothelial cells by a horizontal transfer of mRNA Blood 110, 2440-2448. doi: 10.1182/blood-2007-03-078709

Dernbach, E., Urbich, C., Brandes, R. P., Hofmann, W. K., Zeiher, A. M., and Dimmeler, S. (2004). Antioxidative stress-associated genes in circulating progenitor cells: evidence for enhanced resistance against oxidative stress. Blood 104, 3591-3597. doi: 10.1182/blood-2003-12-4103

Doherty, J. R., and Cleveland, J. L. (2013). Targeting lactate metabolism for cancer therapeutics. J. Clin. Invest. 123, 3685-3692. doi: 10.1172/jci69741

Dong, Y., Sun, Q., Liu, T., Wang, H., Jiao, K., Xu, J., et al. (2016). Nitrative stress participates in endothelial progenitor cell injury in hyperhomocysteinemia. PLoS ONE 11:e0158672. doi: 10.1371/journal.pone.0158672

Duan, H., Xing, S., Luo, Y., Feng, L., Gramaglia, I., Zhang, Y., et al. (2013). Targeting endothelial CD146 attenuates neuroinflammation by limiting lymphocyte extravasation to the CNS. Sci. Rep. 3:1687. doi: 10.1038/srep01687

Eelen, G., de Zeeuw, P., Simons, M., and Carmeliet, P. (2015). Endothelial cell metabolism in normal and diseased vasculature. Circ. Res. 116, 1231-1244. doi: 10.1161/circresaha.116.302855

Ehling, M., Adams, S., Benedito, R., and Adams, R. H. (2013). Notch controls retinal blood vessel maturation and quiescence. Development 140, 3051-3061. doi: 10.1242/dev.093351

Ergul, A., Valenzuela, J. P., Fouda, A. Y., and Fagan, S. C. (2015). Cellular connections, microenvironment and brain angiogenesis in diabetes: lost communication signals in the post-stroke period. Brain Res. 1623, 81-96. doi: 10.1016/j.brainres.2015.02.045

Fadini, G. P., Losordo, D., and Dimmeler, S. (2012). Critical reevaluation of endothelial progenitor cell phenotypes for therapeutic and diagnostic use. Circ. Res. 110, 624-637. doi: 10.1161/circresaha.111.243386

Finney, M. R., Greco, N. J., Haynesworth, S. E., Martin, J. M., Hedrick, D. P., Swan, J. Z., et al. (2006). Direct comparison of umbilical cord blood versus bone marrow-derived endothelial precursor cells in mediating neovascularization in response to vascular ischemia. Biol. Blood Marrow Transplant. 12, 585-593. doi: 10.1016/j.bbmt.2005.12.037

Flores-Nascimento, M. C., Alessio, A. M., de Andrade Orsi, F. L., and AnnichinoBizzacchi, J. M. (2015). CD144, CD146 and VEGFR-2 properly identify circulating endothelial cell. Rev. Bras. Hematol. Hemoter. 37, 98-102. doi: 10. 1016/j.bjhh.2014.11.014

Fraisl, P., Mazzone, M., Schmidt, T., and Carmeliet, P. (2009). Regulation of angiogenesis by oxygen and metabolism. Dev. Cell 16, 167-179. doi: 10.1016/ j.devcel.2009.01.003

Freeman, L. R., and Keller, J. N. (2012). Oxidative stress and cerebral endothelial cells: regulation of the blood-brain-barrier and antioxidant based interventions. Biochim. Biophys. Acta 1822, 822-829. doi: 10.1016/j.bbadis. 2011.12.009

Fukuda, S., Nagano, M., Yamashita, T., Kimura, K., Tsuboi, I., Salazar, G., et al. (2013). Functional endothelial progenitor cells selectively recruit neurovascular protective monocyte-derived $\mathrm{F} 4 / 80(+) / \mathrm{Ly} 6 \mathrm{c}(+)$ macrophages in a mouse model of retinal degeneration. Stem Cells 31, 2149-2161. doi: 10.1002/ stem.1469

Gao, X., Qian, J., Zheng, S., Changyi, Y., Zhang, J., Ju, S., et al. (2014). Overcoming the blood-brain barrier for delivering drugs into the brain by using adenosine receptor nanoagonist. ACS Nano 8, 3678-3689. doi: 10.1021/nn5003375

Goligorsky, M. S. (2014). Endothelial progenitor cells: from senescence to rejuvenation. Semin. Nephrol. 34, 365-373. doi: 10.1016/j.semnephrol.2014. 06.003

Grant, G. A., and Janigro, D. (2006). "Vasculogenesis and Angiogenesis," in The Cell Cycle in the Central Nervous System, ed D. Janigro (Totowa, NJ: Humana Press), 31-41.

Griep, L. M., Wolbers, F., de Wagenaar, B., ter Braak, P. M., Weksler, B. B., Romero, I. A., et al. (2013). BBB on chip: microfluidic platform to mechanically and biochemically modulate blood-brain barrier function. Biomed. Microdevices 15, 145-150. doi: 10.1007/s10544-012-9699-7

Guarani, V., Deflorian, G., Franco, C. A., Krüger, M., Phng, L. K., Bentley, K., et al. (2011). Acetylation-dependent regulation of endothelial Notch signalling by the SIRT1 deacetylase. Nature 473, 234-238. doi: 10.1038/nature09917

Harjes, U., Bridges, E., McIntyre, A., Fielding, B. A., and Harris, A. L. (2014). Fatty acid-binding protein 4 , a point of convergence for angiogenic and metabolic signaling pathways in endothelial cells. J. Biol. Chem. 289, 23168-23176. doi: 10. 1074/jbc.M114.576512 
Heissig, B., Werb, Z., Rafii, S., and Hattori, K. (2003). Role of c-kit/Kit ligand signaling in regulating vasculogenesis. Thromb. Haemost. 90, 570-576. doi: 10. 1160/th03-03-0188

Hellström, M., Phng, L. K., Hofmann, J. J., Wallgard, E., Coultas, L., Lindblom, P., et al. (2007). Dll4 signalling through Notch1 regulates formation of tip cells during angiogenesis. Nature 445, 776-780. doi: 10.1038/nature05571

Horenstein, A. L., Chillemi, A., Quarona, V., Zito, A., Roato, I., Morandi, F., et al. (2015). NAD(+)-Metabolizing ectoenzymes in remodeling tumor-host interactions: the human myeloma model. Cells 4, 520-537. doi: 10.3390/ cells 4030520

Horenstein, A. L., Chillemi, A., Zaccarello, G., Bruzzone, S., Quarona, V., Zito, A., et al. (2013). A CD38/CD203a/CD73 ectoenzymatic pathway independent of CD39 drives a novel adenosinergic loop in human $\mathrm{T}$ lymphocytes. Oncoimmunology 2:e26246. doi: 10.4161/onci.26246

Hu, M., and Liu, B. (2016). Resveratrol attenuates lipopolysaccharide-induced dysfunction of blood-brain barrier in endothelial cells via AMPK activation. Korean J. Physiol. Pharmacol. 20, 325-332. doi: 10.4196/kjpp.2016.20.4.325

Huang, S. H., Wang, L., Chi, F., Wu, C. H., Cao, H., Zhang, A., et al. (2013a). Circulating brain microvascular endothelial cells (cBMECs) as potential biomarkers of the blood-brain barrier disorders caused by microbial and non-microbial factors. PLoS ONE 8:e62164. doi: 10.1371/journal.pone.0062164

Huang, X. T., Zhang, Y. Q., Li, S. J., Li, S. H., Tang, Q., Wang, Z. T., et al. (2013b). Intracerebroventricular transplantation of ex vivo expanded endothelial colony-forming cells restores blood-brain barrier integrity and promotes angiogenesis of mice with traumatic brain injury. J. Neurotrauma 30 , 2080-2088. doi: 10.1089/neu.2013.2996

Ii, M., Takeshita, K., Ibusuki, K., Luedemann, C., Wecker, A., Eaton, E., et al. (2010). Notch signaling regulates endothelial progenitor cell activity during recovery from arterial injury in hypercholesterolemic mice. Circulation 121, 1104-1112. doi: 10.1161/circulationaha.105.553917

Janzer, R. C., Lobrinus, J. A., Darekar, P., and Juillerat, L. (1993). Astrocytes secrete a factor inducing the expression of HT7-protein and neurothelin in endothelial cells of chorioallantoic vessels. Adv. Exp. Med. Biol. 331, 217-221.

Jiang, B., Jen, M., Perrin, L., Wertheim, J. A., and Ameer, G. A. (2015). SIRT1 overexpression maintains cell phenotype and function of endothelial cells derived from induced pluripotent stem cells. Stem Cells Dev. 24, 2740-2745. doi: $10.1089 / \mathrm{scd} .2015 .0191$

Jiang, M., Wang, B., Wang, C., He, B., Fan, H., Guo, T. B., et al. (2008). Angiogenesis by transplantation of HIF-1 alpha modified EPCs into ischemic limbs. J. Cell. Biochem. 103, 321-334. doi: 10.1002/jcb.21416

Kaczorowski, C. C., Stodola, T. J., Hoffmann, B. R., Prisco, A. R., Liu, P. Y., Didier, D. N., et al. (2013). Targeting the endothelial progenitor cell surface proteome to identify novel mechanisms that mediate angiogenic efficacy in a rodent model of vascular disease. Physiol. Genomics 45, 999-1011. doi: 10.1152/ physiolgenomics.00097.2013

Kanzler, I., Tuchscheerer, N., Steffens, G., Simsekyilmaz, S., Konschalla, S., Kroh, A., et al. (2013). Differential roles of angiogenic chemokines in endothelial progenitor cell-induced angiogenesis. Basic Res. Cardiol. 108, 310-310. doi: 10. 1007/s00395-012-0310-4

Karcher, J. R., Hoffmann, B. R., Liu, P., Liu, Y., Liang, M., and Greene, A. S. (2015). Genome-wide epigenetic and proteomic analysis reveals altered Notch signaling in EPC dysfunction. Physiol. Rep. 3:e12358. doi: 10.14814/phy2.12358

Kasparov, S. (2016). Are astrocytes the pressure-reservoirs of lactate in the brain? Cell Metab. 23, 1-2. doi: 10.1016/j.cmet.2015.11.001

Kaushik, D. K., Hahn, J. N., and Yong, V. W. (2015). EMMPRIN, an upstream regulator of MMPs, in CNS biology. Matrix Biol. 44-46, 138-146. doi: 10.1016/ j.matbio.2015.01.018

Kazmierski, M., Wojakowski, W., Michalewska-Wludarczyk, A., Podolecka, E., Kotowski, M., Machalinski, B., et al. (2015). Exercise-induced mobilisation of endothelial progenitor cells in patients with premature coronary heart disease. Kardiol. Pol. 73, 411-418. doi: 10.5603/KP.a2014.0248

Khilazheva, E. D., Boytsova, E. B., Pozhilenkova, E. A., Solonchuk, Y. R., and Salmina, A. B. (2015). Obtaining a three-cell model of a neurovascular unit in vitro. Cell Tissue Biol. 9, 447-451. doi: 10.1134/s1990519x15060048

Kim, D. G., and Bynoe, M. S. (2015). A2A adenosine receptor regulates the human blood-brain barrier permeability. Mol. Neurobiol. 52, 664-678. doi: 10.1007/ s12035-014-8879-2
Kushner, E. J., Hoetzer, G. L., MacEneaney, O. J., Greiner, J. J., Cech, J. N., Stauffer, B. L., et al. (2008). Aging and EPC release of proangiogenic factors. FASEB J. 22(1 Suppl.), 746-711.

Kushner, E. J., MacEneaney, O. J., Weil, B. R., Greiner, J. J., Stauffer, B. L., and DeSouza, C. A. (2011). Aging is associated with a proapoptotic endothelial progenitor cell phenotype. J. Vasc. Res. 48, 408-414. doi: 10.1159/000324837

Lamagna, C., and Bergers, G. (2006). The bone marrow constitutes a reservoir of pericyte progenitors. J. Leukoc. Biol. 80, 677-681. doi: 10.1189/jlb.0506309

Landor, S. K., Mutvei, A. P., Mamaeva, V., Jin, S., Busk, M., Borra, R., et al. (2011). Hypo- and hyperactivated Notch signaling induce a glycolytic switch through distinct mechanisms. Proc. Natl. Acad. Sci. U.S.A. 108, 18814-18819. doi: 10. 1073/pnas.1104943108

Lee, S. T., Chu, K., Jung, K. H., Jeon, D., Bahn, J. J., Kim, J. H., et al. (2010). Dysfunctional characteristics of circulating angiogenic cells in Alzheimer's disease. J. Alzheimers. Dis. 19, 1231-1240. doi: 10.3233/jad-2010-1315

Lee, S. T., Chu, K., Jung, K. H., Park, H. K., Kim, D. H., Bahn, J. J., et al. (2009). Reduced circulating angiogenic cells in Alzheimer disease. Neurology 72, 1858-1863. doi: 10.1212/WNL.0b013e3181a711f4

Leeper, N. J., Hunter, A. L., and Cooke, J. P. (2010). Stem cell therapy for vascular regeneration: adult, embryonic, and induced pluripotent stem cells. Circulation 122, 517-526. doi: 10.1161/circulationaha.109.881441

Li, W. D., Du, X. L., Qian, A. M., Hu, N., Kong, L. S., Wei, S., et al. (2015a). Metformin regulates differentiation of bone marrow-derived endothelial progenitor cells via multiple mechanisms. Biochem. Biophys. Res. Commun. 465, 803-809. doi: 10.1016/j.bbrc.2015.08.091

Li, Y. F., Ren, L. N., Guo, G., Cannella, L. A., Chernaya, V., Samuel, S., et al. (2015b). Endothelial progenitor cells in ischemic stroke: an exploration from hypothesis to therapy. J. Hematol. Oncol. 8, 33. doi: 10.1186/s13045-0150130-8

Lian, X., Bao, X., Al-Ahmad, A., Liu, J., Wu, Y., Dong, W., et al. (2014). Efficient differentiation of human pluripotent stem cells to endothelial progenitors via small-molecule activation of WNT signaling. Stem Cell Rep. 3, 804-816. doi: 10. 1016/j.stemcr.2014.09.005

Lin, R., Cai, J., Nathan, C., Wei, X., Schleidt, S., Rosenwasser, R., et al. (2015b). Neurogenesis is enhanced by stroke in multiple new stem cell niches along the ventricular system at sites of high BBB permeability. Neurobiol. Dis. 74, 229-239. doi: 10.1016/j.nbd.2014.11.016

Lin, R. Z., Hatch, A., Antontsev, V. G., Murthy, S. K., and Melero-Martin, J. M. (2015a). Microfluidic capture of endothelial colony-forming cells from human adult peripheral blood: phenotypic and functional validation in vivo. Tissue Eng. Part C Methods 21, 274-283. doi: 10.1089/ten.tec.2014.0323

Lippmann, E. S., Azarin, S. M., Kay, J. E., Nessler, R. A., Wilson, H. K., AlAhmad, A., et al. (2012). Derivation of blood-brain barrier endothelial cells from human pluripotent stem cells. Nat. Biotechnol. 30, 783-791. doi: 10.1038/ nbt.2247

Lippmann, E. S., Weidenfeller, C., Svendsen, C. N., and Shusta, E. V. (2011). Blood-brain barrier modeling with co-cultured neural progenitor cell-derived astrocytes and neurons. J. Neurochem. 119, 507-520. doi: 10.1111/j.1471-4159. 2011.07434.x

Liu, K., Chi, L., Guo, L., Liu, X., Luo, C., Zhang, S., et al. (2008). The interactions between brain microvascular endothelial cells and mesenchymal stem cells under hypoxic conditions. Microvasc. Res. 75, 59-67. doi: http://dx.doi.org/10.1016/j.mvr.2007.06.003

Liu, Y., Tang, G., Li, Y., Wang, Y., Chen, X., Gu, X., et al. (2014). Metformin attenuates blood-brain barrier disruption in mice following middle cerebral artery occlusion. J. Neuroinflammation 11, 177. doi: 10.1186/s12974-014$0177-4$

Liu, Z., Sneve, M., Haroldson, T. A., Smith, J. P., and Drewes, L. R. (2016). Regulation of monocarboxylic acid transporter 1 trafficking by the canonical wnt/beta-catenin pathway in rat brain endothelial cells requires cross-talk with notch signaling. J. Biol. Chem. 291, 8059-8069. doi: 10.1074/jbc.M115. 710277

Loges, S., Fehse, B., Brockmann, M. A., Lamszus, K., Butzal, M., Guckenbiehl, M., et al. (2004). Identification of the adult human hemangioblast. Stem Cells Dev. 13, 229-242. doi: 10.1089/154732804323099163

Loibl, M., Binder, A., Herrmann, M., Duttenhoefer, F., Richards, R. G., Nerlich, M., et al. (2014). Direct cell-cell contact between mesenchymal stem cells and 
endothelial progenitor cells induces a pericyte-like phenotype in vitro. Biomed Res. Int. 2014:395781. doi: 10.1155/2014/395781

Lu, A., Wang, L., and Qian, L. (2015). The role of eNOS in the migration and proliferation of bone-marrow derived endothelial progenitor cells and in vitro angiogenesis. Cell Biol. Int. 39, 484-490. doi: 10.1002/cbin. 10405

Martinez-Outschoorn, U. E., Prisco, M., Ertel, A., Tsirigos, A., Lin, Z., Pavlides, S., et al. (2011). Ketones and lactate increase cancer cell "stemness", driving recurrence, metastasis and poor clinical outcome in breast cancer: achieving personalized medicine via metabolo-genomics. Cell Cycle 10, 1271-1286. doi: $10.4161 / \mathrm{cc} \cdot 10.8 .15330$

Matsushita, T., Kibayashi, T., Katayama, T., Yamashita, Y., Suzuki, S., Kawamata, J., et al. (2011). Mesenchymal stem cells transmigrate across brain microvascular endothelial cell monolayers through transiently formed inter-endothelial gaps. Neurosci. Lett. 502, 41-45. doi: 10.1016/j.neulet.2011.07.021

Mazumdar, J., O’Brien, W. T., Johnson, R. S., LaManna, J. C., Chavez, J. C., Klein, P. S., et al. (2010). O(2) regulates stem cells through Wnt/ $\beta$-catenin signalling. Nat. Cell Biol. 12, 1007-1013. doi: 10.1038/ncb2102

Medina, R. J., O’Neill, C. L., Sweeney, M., Guduric-Fuchs, J., Gardiner, T. A., Simpson, D. A., et al. (2010). Molecular analysis of endothelial progenitor cell (EPC) subtypes reveals two distinct cell populations with different identities. BMC Med. Genomics 3:18. doi: 10.1186/17558794-3-18

Milovanova, T. N., Bhopale, V. M., Sorokina, E. M., Moore, J. S., Hunt, T. K., Hauer-Jensen, M., et al. (2008a). Lactate stimulates vasculogenic stem cells via the thioredoxin system and engages an autocrine activation loop involving hypoxia-inducible factor 1. Mol. Cell. Biol. 28, 6248-6261. doi: 10.1128/mcb. 00795-08

Milovanova, T. N., Bhopale, V. M., Sorokina, E. M., Moore, J. S., Hunt, T. K., Hauer-Jensen, M., et al. (2008b). Lactate stimulates vasculogenic stem cells via the thioredoxin system and engages an autocrine activation loop involving hypoxia-inducible factor 1. Mol. Cell. Biol. 28, 6248-6261. doi: 10.1128/mcb. 00795-08

Minami, Y., Nakajima, T., Ikutomi, M., Morita, T., Komuro, I., Sata, M., et al. (2015). Angiogenic potential of early and late outgrowth endothelial progenitor cells is dependent on the time of emergence. Int. J. Cardiol. 186, 305-314. doi: 10.1016/j.ijcard.2015.03.166

Mosienko, V., Teschemacher, A. G., and Kasparov, S. (2015). Is L-lactate a novel signaling molecule in the brain? J. Cereb. Blood Flow Metab. 35, 1069-1075. doi: $10.1038 / \mathrm{jcbfm} .2015 .77$

Muramatsu, T. (2016). Basigin (CD147), a multifunctional transmembrane glycoprotein with various binding partners. J. Biochem. 159, 481-490. doi: 10. $1093 / \mathrm{jb} / \mathrm{mvv} 127$

Newman, J. C., and Verdin, E. (2014). $\beta$-hydroxybutyrate: much more than a metabolite. Diabetes Res. Clin. Pract. 106, 173-181. doi: 10.1016/j.diabres.2014. 08.009

O'Carroll, S. J., Kho, D. T., Wiltshire, R., Nelson, V., Rotimi, O., Johnson, R., et al. (2015). Pro-inflammatory TNFalpha and IL-1beta differentially regulate the inflammatory phenotype of brain microvascular endothelial cells. J. Neuroinflammation 12, 131. doi: 10.1186/s12974-015-0346-0

Oldendorf, W. H., Cornford, M. E., and Brown, W. J. (1977). The large apparent work capability of the blood-brain barrier: a study of the mitochondrial content of capillary endothelial cells in brain and other tissues of the rat. Ann. Neurol. 1, 409-417. doi: 10.1002/ana.410010502

Pamies, D., Hartung, T., and Hogberg, H. T. (2014). Biological and medical applications of a brain-on-a-chip. Exp. Biol. Med. 239, 1096-1107. doi: 10.1177/ 1535370214537738

Panfoli, I., Cassanello, M., Bruschettini, M., Colella, M., Cerone, R., Ravera, S., et al. (2016). Why do premature newborn infants display elevated blood adenosine levels? Med. Hypotheses 90, 53-56. doi: 10.1016/j.mehy.2016.03.007

Pate, K. T., Stringari, C., Sprowl-Tanio, S., Wang, K., TeSlaa, T., Hoverter, N. P., et al. (2014). Wnt signaling directs a metabolic program of glycolysis and angiogenesis in colon cancer. EMBO J. 33, 1454-1473. doi: 10.15252/embj. 201488598

Paul, G., Özen, I., Christophersen, N. S., Reinbothe, T., Bengzon, J., Visse, E., et al. (2012). The adult human brain harbors multipotent perivascular mesenchymal stem cells. PLoS ONE 7:e35577. doi: 10.1371/journal.pone.0035577
Perrucci, G. L., Straino, S., Corlianò, M., Scopece, A., Napolitano, M., Berk, B. C., et al. (2016). Cyclophilin A modulates bone marrow-derived CD117+ cells and enhances ischemia-induced angiogenesis via the SDF-1/CXCR4 axis. Int. J. Cardiol. 212, 324-335. doi: 10.1016/j.ijcard.2016.03.082

Plouffe, B. D., Kniazeva, T., Mayer, J. E., Jr., Murthy, S. K., and Sales, V. L. (2009). Development of microfluidics as endothelial progenitor cell capture technology for cardiovascular tissue engineering and diagnostic medicine. FASEB J. 23, 3309-3314. doi: 10.1096/fj.09-130260

Poittevin, M., Bonnin, P., Pimpie, C., Rivière, L., Sebrié, C., Dohan, A., et al. (2015). Diabetic microangiopathy: impact of impaired cerebral vasoreactivity and delayed angiogenesis after permanent middle cerebral artery occlusion on stroke damage and cerebral repair in mice. Diabetes 64, 999-1010. doi: 10.2337/ db14-0759

Pombero, A., Garcia-Lopez, R., and Martinez, S. (2016). Brain mesenchymal stem cells: physiology and pathological implications. Dev. Growth Differ. 58, 469-480. doi: $10.1111 /$ dgd.12296

Prakash, R., Somanath, P. R., El-Remessy, A. B., Kelly-Cobbs, A., Stern, J. E., DoreDuffy, P., et al. (2012). Enhanced cerebral but not peripheral angiogenesis in the Goto-Kakizaki model of type 2 diabetes involves VEGF and peroxynitrite signaling. Diabetes 61, 1533-1542. doi: 10.2337/db11-1528

Price, N. L., Gomes, A. P., Ling, A. J. Y., Duarte, F. V., Martin-Montalvo, A., North, B. J., et al. (2012). SIRT1 is required for AMPK activation and the beneficial effects of resveratrol on mitochondrial function. Cell Metab. 15, 675-690. doi: 10.1016/j.cmet.2012.04.003

Prisco, A. R., Prisco, M. R., Carlson, B. E., and Greene, A. S. (2015). TNFalpha increases endothelial progenitor cell adhesion to the endothelium by increasing bond expression and affinity. Am. J. Physiol. Heart Circ. Physiol. 308, H1368-H1381. doi: 10.1152/ajpheart.00496.2014

Quarona, V., Ferri, V., Chillemi, A., Bolzoni, M., Mancini, C., Zaccarello, G., et al. (2015). Unraveling the contribution of ectoenzymes to myeloma life and survival in the bone marrow niche. Ann. N. Y. Acad. Sci. 1335, 10-22. doi: 10. $1111 /$ nyas. 12485

Rae, P. C., Kelly, R. D., Egginton, S., and St John, J. C. (2011a). Angiogenic potential of endothelial progenitor cells and embryonic stem cells. Vasc. Cell 3, 1-15. doi: $10.1186 / 2045-824 x-3-11$

Rae, P. C., Kelly, R. D., Egginton, S., and St John, J. C. (2011b). Angiogenic potential of endothelial progenitor cells and embryonic stem cells. Vasc. Cell 3, 11. doi: 10. $1186 / 2045-824 x-3-11$

Richardson, M. R., and Yoder, M. C. (2011). Endothelial progenitor cells: quo vadis? J. Mol. Cell. Cardiol. 50, 266-272. doi: 10.1016/j.yjmcc.2010. 07.009

Rolland-Turner, M., Goretti, E., Bousquenaud, M., Léonard, F., Nicolas, C., Zhang, L., et al. (2013). Adenosine stimulates the migration of human endothelial progenitor cells. Role of CXCR4 and microRNA-150. PLoS ONE 8:e54135. doi: 10.1371/journal.pone.0054135

Rousset, C. I., Leiper, F. C., Kichev, A., Gressens, P., Carling, D., Hagberg, H., et al. (2015). A dual role for AMP-activated protein kinase (AMPK) during neonatal hypoxic-ischaemic brain injury in mice. J. Neurochem. 133, 242-252. doi: 10. 1111/jnc. 13034

Sakolish, C. M., Esch, M. B., Hickman, J. J., Shuler, M. L., and Mahler, G. J. (2016). Modeling barrier tissues in vitro: methods, achievements, and challenges. EBioMedicine 5, 30-39. doi: 10.1016/j.ebiom.2016.02.023

Salmina, A. B., Inzhutova, A. I., Morgun, A. V., Okuneva, O. S., Malinovskaia, N. A., Lopatina, O. L., et al. (2012). NAD+-converting enzymes in neuronal and glial cells: CD38 as a novel target for neuroprotection. Vestn. Ross Akad. Med. Nauk 10, 29-37.

Salmina, A. B., Kuvacheva, N. V., Morgun, A. V., Komleva, Y. K., Pozhilenkova, E. A., Lopatina, O. L., et al. (2015). Glycolysis-mediated control of bloodbrain barrier development and function. Int. J. Biochem. Cell Biol. 64, 174-184. doi: 10.1016/j.biocel.2015.04.005

Salmina, A. B., Morgun, A. V., Kuvacheva, N. V., Pozhilenkova, E. A., Solonchuk, I. R., Lopatina, O. L., et al. (2014). Endothelial progenitor cells in cerebral endothelial development and repair. Curr. Technol.Med. 6, 9. doi: 10.1186/ s13041-016-0193-7

Salmina, A. B., Okuneva, O. S., Malinovskaya, N. A., Zykova, L. D., Fursov, A. A., Morgun, A. V., et al. (2009). Changes in expression and activity of CD38 in astroglial cells after impairment of the neuron-glia relationship in the brain 
induced by perinatal hypoxia-ischemia. Neurochem. J. 3, 207-213. doi: 10.1134/ s181971240903009x

Saunders, N. R., Daneman, R., Dziegielewska, K. M., and Liddelow, S. A. (2013). Transporters of the blood-brain and blood-CSF interfaces in development and in the adult. Mol. Aspects Med. 34, 742-752. doi: 10.1016/j.mam.2012. 11.006

Saunders, N. R., Dziegielewska, K. M., Møllgård, K., Habgood, M. D., Wakefield, M. J., Lindsay, H., et al. (2015). Influx mechanisms in the embryonic and adult rat choroid plexus: a transcriptome study. Front. Neurosci. 9:123. doi: 10.3389/ fnins.2015.00123

Sawada, N., Jiang, A., Takizawa, F., Safdar, A., Manika, A., Tesmenitsky, Y., et al. (2014). Endothelial PGC-1alpha mediates vascular dysfunction in diabetes. Cell Metab. 19, 246-258. doi: 10.1016/j.cmet.2013.12.014

Schlosshauer, B., and Herzog, K. H. (1990). Neurothelin: an inducible cell surface glycoprotein of blood-brain barrier-specific endothelial cells and distinct neurons. J. Cell Biol. 110, 1261-1274.

Schmidt, A., Brixius, K., and Bloch, W. (2007). Endothelial precursor cell migration during vasculogenesis. Circ. Res. 101, 125-136. doi: 10.1161/circresaha.107. 148932

Schoors, S., Bruning, U., Missiaen, R., Queiroz, K. C., Borgers, G., Elia, I., et al. (2015). Fatty acid carbon is essential for dNTP synthesis in endothelial cells. Nature 520, 192-197. doi: 10.1038/nature14362

Schrage, A., Loddenkemper, C., Erben, U., Lauer, U., Hausdorf, G., Jungblut, P. R., et al. (2008). Murine CD146 is widely expressed on endothelial cells and is recognized by the monoclonal antibody ME-9F1. Histochem. Cell Biol. 129, 441-451. doi: 10.1007/s00418-008-0379-x

Smadja, D. M., Bièche, I., Helley, D., Laurendeau, I., Simonin, G., Muller, L., et al. (2007). Increased VEGFR2 expression during human late endothelial progenitor cells expansion enhances in vitro angiogenesis with up-regulation of integrin alpha(6). J. Cell. Mol. Med. 11, 1149-1161. doi: 10.1111/j.1582-4934. 2007.00090.x

Smith, J. P., Uhernik, A. L., Li, L., Liu, Z., and Drewes, L. R. (2012). Regulation of Mct1 by cAMP-dependent internalization in rat brain endothelial cells. Brain Res. 1480, 1-11. doi: 10.1016/j.brainres.2012.08.026

Son, M. J., Kwon, Y., Son, T., and Cho, Y. S. (2016). Restoration of mitochondrial $\mathrm{NAD}+$ levels delays stem cell senescence and facilitates reprogramming of aged somatic cells. Stem Cells 34, 2840-2851. doi: 10.1002/stem.2460

Stalin, J., Harhouri, K., Hubert, L., Subrini, C., Lafitte, D., Lissitzky, J. C., et al. (2013). Soluble melanoma cell adhesion molecule (sMCAM/sCD146) promotes angiogenic effects on endothelial progenitor cells through angiomotin. J. Biol. Chem. 288, 8991-9000. doi: 10.1074/jbc.M112.446518

Stamatovic, S. M., Keep, R. F., and Andjelkovic, A. V. (2008). Brain endothelial cellcell junctions: how to "open" the blood brain barrier. Curr. Neuropharmacol. 6, 179-192. doi: 10.2174/157015908785777210

Stapor, P., Wang, X., Goveia, J., Moens, S., and Carmeliet, P. (2014). Angiogenesis revisited - role and therapeutic potential of targeting endothelial metabolism. J. Cell Sci. 127(Pt 20), 4331-4341. doi: 10.1242/jcs.153908

Stokes, C. L., Cirit, M., and Lauffenburger, D. A. (2015). Physiome-on-achip: the challenge of "scaling" in design, operation, and translation of microphysiological systems. CPT: Pharm. Syst. Pharmacol. 4, 559-562. doi: 10. 1002/psp4.12042

Tang, X., Luo, Y. X., Chen, H. Z., and Liu, D. P. (2014). Mitochondria, endothelial cell function, and vascular diseases. Front. Physiol. 5:175. doi: 10.3389/fphys. 2014.00175

Tenreiro, M. M., Ferreira, R., Bernardino, L., and Brito, M. A. (2016). Cellular response of the blood-brain barrier to injury: potential biomarkers and therapeutic targets for brain regeneration. Neurobiol. Dis. 91, 262-273. doi: 10. 1016/j.nbd.2016.03.014

Tilling, L., Chowienczyk, P., and Clapp, B. (2009). Progenitors in motion: mechanisms of mobilization of endothelial progenitor cells. Br. J. Clin. Pharmacol. 68, 484-492. doi: 10.1111/j.1365-2125.2009.03486.x

Tran, M. T., Zsengeller, Z. K., Berg, A. H., Khankin, E. V., Bhasin, M. K., Kim, W., et al. (2016). PGClalpha drives NAD biosynthesis linking oxidative metabolism to renal protection. Nature 531, 528-532. doi: 10.1038/nature 17184

Tseng, S. Y., Chao, T. H., Li, Y. H., Liu, P. Y., Lee, C. H., Cho, C. L., et al. (2016). Cilostazol improves high glucose-induced impaired angiogenesis in human endothelial progenitor cells and vascular endothelial cells as well as enhances vasculoangiogenesis in hyperglycemic mice mediated by the adenosine monophosphate-activated protein kinase pathway. J. Vasc. Surg. 63 , 1051 e3-1062 e3. doi: 10.1016/j.jvs.2014.10.103

Uhernik, A. L., Tucker, C., and Smith, J. P. (2011). Control of MCT1 function in cerebrovascular endothelial cells by intracellular pH. Brain Res. 1376, 10-22. doi: 10.1016/j.brainres.2010.12.060

Vallon, M., Chang, J., Zhang, H., and Kuo, C. J. (2014). Developmental and pathological angiogenesis in the central nervous system. Cell. Mol. Life Sci. 71, 3489-3506. doi: 10.1007/s00018-014-1625-0

van der Helm, M. W., van der Meer, A. D., Eijkel, J. C., van den Berg, A., and Segerink, L. I. (2016). Microfluidic organ-on-chip technology for blood-brain barrier research. Tissue Barriers 4:e1142493. doi: 10.1080/21688370.2016. 1142493

Vannucci, S. J., and Simpson, I. A. (2003). Developmental switch in brain nutrient transporter expression in the rat. Am. J. Physiol. Endocrinol. Metab. 285, E1127-E1134. doi: 10.1152/ajpendo.00187.2003

Wang, P., Du, H., Zhou, C. C., Song, J., Liu, X., Cao, X., et al. (2014). Intracellular NAMPT-NAD+-SIRT1 cascade improves post-ischaemic vascular repair by modulating Notch signalling in endothelial progenitors. Cardiovasc. Res. 104, 477-488. doi: $10.1093 / \mathrm{cvr} / \mathrm{cvu} 220$

Wang, P., Yang, X., Zhang, Z., Song, J., Guan, Y. F., Zou, D. J., et al. (2016). Depletion of NAD pool contributes to impairment of endothelial progenitor cell mobilization in diabetes. Metab. Clin. Exp. 65, 852-862. doi: 10.1016/j. metabol.2016.03.006

Wang, X. B., Huang, J., Zou, J. G., Su, E. B., Shan, Q. J., Yang, Z. J., et al. (2007). Effects of resveratrol on number and activity of endothelial progenitor cells from human peripheral blood. Clin. Exp. Pharmacol. Physiol. 34, 1109-1115. doi: $10.1111 / j .1440-1681.2007 .04667 . x$

Winkler, E. A., Sagare, A. P., and Zlokovic, B. V. (2014). The pericyte: a forgotten cell type with important implications for Alzheimer's disease? Brain Pathol. 24, 371-386. doi: 10.1111/bpa.12152

Xia, L., Wang, X. X., Hu, X. S., Guo, X. G., Shang, Y. P., Chen, H. J., et al. (2008). Resveratrol reduces endothelial progenitor cells senescence through augmentation of telomerase activity by Akt-dependent mechanisms. Br. J. Pharmacol. 155, 387-394. doi: 10.1038/bjp.2008.272

Xu, D., and Hemler, M. E. (2005). Metabolic activation-related CD147-CD98 complex. Mol. Cell. Proteomics 4, 1061-1071. doi: 10.1074/mcp.M400207MCP200

Xu, Y., An, X., Guo, X., Habtetsion, T. G., Wang, Y., Xu, X., et al. (2014). Endothelial 6-phosphofructo-2-kinase (PFKFB3) plays a critical role in angiogenesis. Arterioscler. Thromb. Vasc. Biol. 34, 1231-1239. doi: 10.1161/ atvbaha.113.303041

Yamada, M. K. (2016). Angiogenesis in refractory depression: A possible phenotypic target to avoid the blood brain barrier. Drug Discov. Ther. 10, 74-78. doi: $10.5582 /$ ddt.2016.01003

Yang, H., Borg, T. K., Ma, Z., Xu, M., Wetzel, G., Saraf, L. V., et al. (2016). Biochip-based study of unidirectional mitochondrial transfer from stem cells to myocytes via tunneling nanotubes. Biofabrication 8:015012. doi: 10.1088/17585090/8/1/015012

Yasuda, K., Khandare, A., Burianovskyy, L., Maruyama, S., Zhang, F., Nasjletti, A., et al. (2011). Tunneling nanotubes mediate rescue of prematurely senescent endothelial cells by endothelial progenitors: exchange of lysosomal pool. Aging 3, 597-608. doi: 10.18632/aging.100341

Yiu, K. H., and Tse, H. F. (2014). Specific role of impaired glucose metabolism and diabetes mellitus in endothelial progenitor cell characteristics and function. Arterioscler. Thromb. Vasc. Biol. 34, 1136-1143. doi: 10.1161/atvbaha.114. 302192

Yoder, M. C. (2012). Human Endothelial Progenitor Cells. Cold Spring Harb. Perspect. Med. 2:a006692. doi: 10.1101/cshperspect.a006692

Zhang, H., Ryu, D., Wu, Y., Gariani, K., Wang, X., Luan, P., et al. (2016). $\mathrm{NAD}+$ repletion improves mitochondrial and stem cell function and enhances life span in mice. Science 352, 1436-1443. doi: 10.1126/science. aaf 2693

Zhang, M., Malik, A. B., and Rehman, J. (2014). Endothelial progenitor cells and vascular repair. Curr. Opin. Hematol. 21, 224-228. doi: 10.1097/moh. 0000000000000041 
Zhao, Y. H., Yuan, B., Chen, J., Feng, D. H., Zhao, B., Qin, C., et al. (2013). Endothelial progenitor cells: therapeutic perspective for ischemic stroke. CNS Neurosci. Ther. 19, 67-75. doi: 10.1111/cns.12040

Zhao, Z., Hu, J., Gao, X., Liang, H., and Liu, Z. (2014). Activation of AMPK attenuates lipopolysaccharide-impaired integrity and function of blood-brain barrier in human brain microvascular endothelial cells. Exp. Mol. Pathol. 97, 386-392. doi: 10.1016/j.yexmp.2014.09.006

Zhu, J. H., Chen, J. Z., Wang, X. X., Xie, X. D., Sun, J., and Zhang, F. R. (2006). Homocysteine accelerates senescence and reduces proliferation of endothelial progenitor cells. J. Mol. Cell. Cardiol. 40, 648-652. doi: 10.1016/j.yjmcc.2006. 01.011
Conflict of Interest Statement: The authors declare that the research was conducted in the absence of any commercial or financial relationships that could be construed as a potential conflict of interest.

Copyright (C) 2016 Malinovskaya, Komleva, Salmin, Morgun, Shuvaev, Panina, Boitsova and Salmina. This is an open-access article distributed under the terms of the Creative Commons Attribution License (CC BY). The use, distribution or reproduction in other forums is permitted, provided the original author(s) or licensor are credited and that the original publication in this journal is cited, in accordance with accepted academic practice. No use, distribution or reproduction is permitted which does not comply with these terms. 